\title{
La industria lítica del yacimiento achelense de Torralba (Soria, España). Colecciones marqués de Cerralbo y Howell
}

\author{
The lithic industry of the Acheulean site of Torralba (Soria, Spain): the Marquis of \\ Cerralbo and Howell collections
}

\author{
Borja Sánchez-Cervera (*) \\ Manuel Santonja Gómez (***) \\ Alfredo Pérez-González $(* *)$ \\ Manuel Domínguez-Rodrigo (**) \\ Laura Sánchez-Romero $\left({ }^{* *}\right)(* * * *)$
}

\section{RESUMEN}

Torralba es un yacimiento del Pleistoceno medio, con dataciones numéricas que le sitúan en el MIS 7 $(191 / 243 \mathrm{ka})$. Su industria, que procede de niveles fluviales y se encuentra fundamentalmente en posición secundaria, fue elaborada sobre materias primas introducidas desde distancias que pueden alcanzar varias decenas de kilómetros. El estudio tecno-económico de las series industriales obtenidas en las excavaciones realizadas por el marqués de Cerralbo (1909-1913) y Clark Howell (1961-1963) confirma la identidad achelense de la industria y la realización de procesos de producción, configuración y mantenimiento en el yacimiento, aunque al menos una parte del macroutillaje fue introducida ya configurada en el mismo. Se identifican aspectos tecnológicos singulares en el contexto del achelense europeo, como el uso frecuente del sílex en la elaboración de hendedores.

(*) Asociación El Hombre y el Medio. Madrid. España. C/ Miguel Corral Aragón 12, Portal A, Bajo C. 28770 Colmenar Viejo. Madrid. Correo e.: borjascervera@hotmail.com

(**) Centro Nacional de Investigación sobre la Evolución Humana (CENIEH). Paseo Sierra de Atapuerca 3. 09003 Burgos. España. Correo e.: Manuel.santonja@cenieh.es; Alfredo.perez@cenieh.es

(***) Dpto. de Prehistoria, Facultad de Geografía e Historia. Universidad Complutense de Madrid. C/ Profesor Aranguren s/n. 28040 Madrid. España.

$(* * * *)$ Escuela Interuniversitaria de Posgrado en Evolución Humana, Universidad de Burgos. C/ Juan de Austria 1. 09001 Burgos. España. Correo e.: lausanrom@gmail.com

Recibido: 1-IV-2014; aceptado: 23-V-2014.

\begin{abstract}
Torralba is a Middle Pleistocene site, with absolute dates that place it in MIS 7. Its lithic industry comes from fluvial levels and is situated in a secondary position. The raw materials were brought to the site from sources located several tens kilometers away. The techno-economic study of the industrial series obtained in the excavations conducted by Marquis of Cerralbo (1909-1913) and Clark Howell (1961-1963), confirms the Acheulean identity of this industry. Production, configuration and maintenance of the industry were all carried out at the site, although at least some macro-tools were introduced already elaborated. We have identified unusual technological aspects in the context of the European Acheulean, for example the frequent use of flint in developing cleavers.
\end{abstract}

Palabras clave: Península Ibérica; Pleistoceno Medio; Achelense; Torralba; Marqués de Cerralbo; Clark Howell.

Key words: Iberian Peninsula; Middle Pleistocene; Acheulean; Torralba; Marquis of Cerralbo; Clark Howell.

\section{SUPERFICIES EXCAVADAS POR EL MARQUÉS DE CERRALBO Y CLARK HOWELL E INDUSTRIA LÍTICA OBTENIDA}

La investigación clásica de Torralba tuvo lugar en dos fases, la primera de ellas impulsada por el marqués de Cerralbo (1845-1922) entre junio 
de 1909 y septiembre de 1913 y la segunda en 1960-1963 bajo la dirección del profesor norteamericano F. C. Howell (1925-2007) junto a un amplio equipo multidisciplinar del que formaban parte entre otros prestigiosos investigadores K. W. Butzer, E. Aguirre, P. Biberson (1909-1992) y L. G. Freeman (1935-2012). Los resultados de estos trabajos han sido objeto de valoraciones recientes (Santonja et al. 2005; Aguirre 2005) (1) que nos evitan entrar aquí en pormenores y permiten centrarnos en la estratigrafía y el estudio de las series líticas reunidas en ambas etapas en los sectores excavados del yacimiento.

Hay elementos para situar de forma aproximada el sector excavado por el marqués de Cerralbo (2) en Torralba, pero no resulta posible establecer con exactitud sus límites. Tras sus dos primeras campañas situaba la zona intervenida en paralelo a uno de los edificios principales de la estación de ferrocarril (3). En concreto indicaba que la esquina SE de la excavación se encontraba a $10,8 \mathrm{~m}$ de este edificio y a $34 \mathrm{~m}$ del siguiente, y que limitaba al NO con una tubería que llevaba agua a la estación, conducción que aún se conserva. En esas mismas páginas se estimaban en $200 \mathrm{~m}^{2}$ la superficie hasta entonces abierta.

En la campaña de 1961 Howell estableció a partir de una serie de sondeos los posibles límites del yacimiento, dibujando una planta oval que comprendía una superficie aproximada de $3800 \mathrm{~m}^{2}$. En ésa y las siguientes campañas de 1962 y 1963 pudo reconocer sedimentos removidos por el marqués de Cerralbo que ayudaban a localizar la posición de sus excavaciones (Howell et al. 1962: fig.5, p. 27; González Echegaray y Freeman 1998: fig. 25). El conjunto de indicios referido hace posible identificar el entorno en que trabajó el marqués de Cerralbo, concretamente en la parte oriental del área delimitada por Howell (Fig. 1). Los sondeos de 1909-1913 se efectuaron en una zona de unos $2000 \mathrm{~m}^{2}$, con $60 \mathrm{~m}$ de longitud en sentido E-O y $35 \mathrm{~m}$ de anchura media en

(1) Sánchez-Cervera Valdés, B. 2009: Estudio de la industria lítica del yacimiento de Torralba (Soria). Memoria de Licenciatura inédita. Universidad Complutense. Madrid.

(2) Enrique de Aguilera y Gamboa, XVII marqués de Cerralbo 1911: Páginas de la Historia patria por mis excavaciones arqueológicas I, Torralba. Inédito. Consultado en el Museo Arqueológico Nacional. Madrid.

(3) Véase n. 2, pp. 59-60. dirección N-S. El marqués de Cerralbo no llegó a excavar la totalidad de esa extensión, pero sin duda la superficie abierta en las seis campañas que llevó a cabo sería muy superior a los $200 \mathrm{~m}^{2}$ mencionados en 1911. Solo una limpieza a fondo de los vertidos que en la actualidad cubren gran parte del yacimiento podría permitir establecer un cálculo preciso.

De las excavaciones del marqués de Cerralbo proceden un total de 552 piezas líticas depositadas actualmente en el Museo Nacional de Ciencias Naturales (330), el Museo Arqueológico Nacional (193) y el Museo Numantino de Soria (29). Otras 8 piezas reflejadas en el inventario del antiguo $\mathrm{Mu}-$ seo Celtibérico no se han conservado (4). Fuera de España hay 4 bifaces y dos retocados en el Peabody Museum (Cambridge, EEUU) y 2 bifaces en el British Museum de Londres, cedidos por el Marqués de Cerralbo a alguno de sus visitantes (Howell et al. 1962: 33). Es un conjunto de materiales sin atribución estratigráfica definida, obtenido en todo caso en la secuencia reconocida por Pedro Palacios en la zona excavada hasta 1911(5). A tenor de lo observado después en las áreas colindantes excavadas por Howell, la casi totalidad de esta industria procedería de los niveles que Palacios describe como un depósito arcilloso de 50-90 $\mathrm{cm}$ de potencia con nódulos y subniveles de gravas calcáreas (cf. Howell et al. 1962: 4-5, apoyado en descripciones de Obermaier y Mac Curdy).

A partir de 1960 Howell continuó la investigación de Torralba. Ese año hace una primera exploración del entorno y tres campañas sucesivas en 1961-1963 (Fig. 1), en las que excavó $1026 \mathrm{~m}^{2}$ (González Echegaray y Freeman 1998: 120). La metodología aplicada comenzaba a cimentarse en los yacimientos al aire libre del Este de África, excavaciones con apoyo geológico y paleontológico que en Europa resultaban una novedad (Santonja y Vega 2002). Durante la primera campaña Butzer (Howell et al. 1962) acometió un estudio geológico y estratigráfico del yacimiento en profundidad (Butzer 1965) que permitió situar los niveles arqueo-paleontológicos y definir una teórica Formación Torralba, integrada por cinco unidades sedimentarias. La Fase II, constituida por niveles de gravas y arenas de carácter claramente fluvial, contenía en efecto la mayor parte de la industria

\footnotetext{
(4) Véase n. 1.

(5) Véase n. 2, p. 201.
}

Trab. Prehist., 72, N. ${ }^{\circ}$ 1, enero-junio 2015, pp. 41-63, ISSN: 0082-5638

doi: $10.3989 /$ tp. 2015.12143 


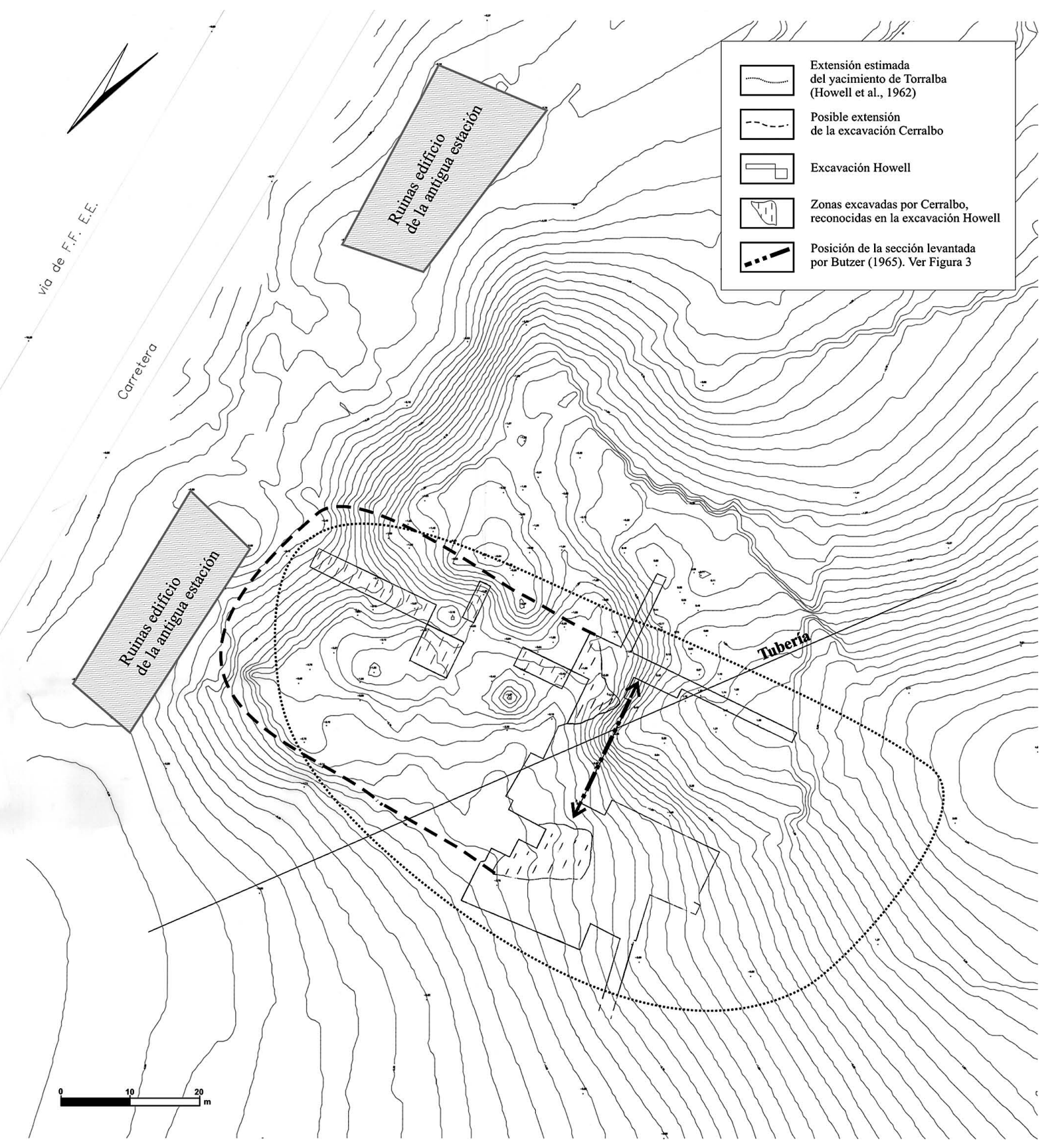

Fig. 1. Yacimiento de Torralba (Soria). Zona en parte excavada por el marqués de Cerralbo (1909-1913) y áreas excavadas por F. C. Howell (1961-1963). Equidistancia de curvas de nivel: $25 \mathrm{~cm}$.

así como las principales concentraciones de fauna (Sesé y Soto 2005), de las que no nos ocuparemos en este estudio.

Las referencias publicadas señalan 182 piezas líticas procedentes de la campaña de 1961
(Howell et al. 1962: 32 ss.) y 689 en las de 196263 (González Echegaray y Freeman 1998: 121), lo que da un total de 871 piezas en el conjunto de las tres campañas. Otras veces se mencionan 887 piezas, de las cuales 102 se consideran inútiles 
para el estudio tecnológico por su avanzado estado de rodamiento (Freeman 1975: 668 ss.). En los fondos del Museo Arqueológico Nacional, destino de los materiales procedentes de estas excavaciones, el total de 977 piezas conservado es superior al incluir posiblemente algunas fuera de estratigrafía. De ellas 29, sin estigmas claros de talla, pueden ser incluidas en la fase de captación. La complejidad del sistema de siglado utilizado (6) hace imposible la atribución estratigráfica sistemática de todos estos materiales, forzando, como en el caso de la colección marqués de Cerralbo, su análisis integral.

Hasta ahora sólo se disponía de estudios parciales de la industria lítica procedente de las excavaciones del marqués de Cerralbo y Howell. Son valoraciones globales (Howell et al. 1962; Biberson 1968; Freeman 1975; González Echegaray y Freeman 1998: 132) y análisis más detallados pero incompletos sobre un número de piezas inferior al conservado en los museos. Ortega estudió 1282 piezas: 533 de la colección del marqués de Cerralbo y 749 de la serie obtenida por Howell (Carbonell et al. 1987; Ortega 1992, 1994) (7). Otras veces se ha trabajado sobre totales menores, como Mosquera (1995) que analiza 782 piezas de la colección Howell. Los últimos estudios citados aplicaron el denominado Sistema Lógico Analítico. Esta metodología de uso no generalizado (Vega 1997) no facilita equivalencias para conceptos (p.e. métodos levallois, discoidal, Quina, conformación, debitage) y términos (raedera, bifaz, hendedor, etc.) normalizados básicos. Tampoco aporta elementos suficientes para comprender los procesos tecnológicos en el marco aquí adoptado de la cadena operativa.

Otros trabajos sobre la industria de Torralba han considerado la procedencia de las materias primas, demostrando que todas las rocas cuarcíticas y silíceas e incluso parte de las calizas son intrusivas (Freeman 1991; Santonja y PérezGonzález 2001; Parcerisas 2006). Las cuarcitas parecen proceder de los conglomerados del Buntsandstein de Miño, $6 \mathrm{~km}$ al NO de Torralba. Los sílex, bastante variados, tendrían fuentes diversas y más lejanas, en un radio de $50 \mathrm{~km}$

(6) Véase n. 1

(7) Enamorado, J. 1992: Aprovechamiento del entorno por los grupos humanos del Pleistoceno Medio en la Península Ibérica. Tesis doctoral inédita. Universidad Complutense. Madrid. en torno al yacimiento. Únicamente las calizas, presentes en los afloramientos cercanos del Trías superior (Formación de Imón) y del Jurásico, serían prácticamente locales.

Se ha especulado con una hipotética captación de todas estas materias primas en el arroyo Mansegal (8) (Mosquera 1998). Sin embargo desde perspectivas geológicas y geomorfológicas (Pérez-González et al. 2005) esta posibilidad carece de fundamento. En la cuenca drenada por el Mansegal no existen afloramientos de cuarcitas y los de sílex son muy limitados, reducidos a algunas nodulizaciones esporádicas intercaladas en las calizas y dolomías jurásicas (Parcerisas 2006). Pudieron aprovecharse ocasionalmente pero en ningún caso aportar la gran variedad de sílex observada en Torralba.

\section{INTERPRETACIONES ESTRATIGRÁFICAS DE TORRALBA EN ÉPOCAS DEL MARQUÉS DE CERRALBO Y F. C. HOWELL}

El marco interpretativo propuesto en las etapas del marqués de Cerralbo (9) y de Howell (Butzer 1965) respecto a la edad y la implantación de Torralba en el paleopaisaje, defendía un idéntico ambiente y su simultaneidad con Ambrona a 2,5 km al Norte. Ambas localidades eran situadas en las orillas de un mismo lago y consideradas estrictamente contemporáneas. Esas conclusiones no se ajustan en absoluto a los conocimientos actuales (Pérez-González et al. 2005). Las edades de Torralba y de Ambrona han sido precisadas en estos últimos años mediante dataciones numéricas, coherentes con las posiciones geomorfológicas donde ambos se encuentran (Fig. 2). Para la unidad estratigráfica media de Ambrona se ha obtenido una fecha de c. $350 \mathrm{ka} E S R / U$ series (Falguères et al. 2006) que permite estimar una edad en torno a 400 ka para la unidad inferior de esa localidad. En Torralba los resultados, directos, son de $209 \pm 22$ ka y $174 \pm 19$ ka OSL (N. Mercier, en Santonja et al. 2014), fechas semejantes a las obtenidas en una terraza a $+20-25 \mathrm{~m}$ del inmediato Alto Henares, en posición morfológica

(8) Véase n. 7, p. 139.

(9) Véase n. 2.

Trab. Prehist., 72, N. ${ }^{\circ}$ 1, enero-junio 2015, pp. 41-63, ISSN: 0082-5638

doi: $10.3989 /$ tp. 2015.12143 


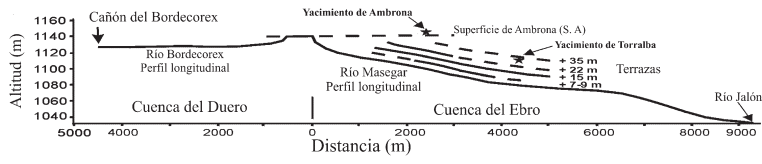

Fig. 2. Situación morfoestratigráfica relativa de los yacimientos de Ambrona y Torralba. El yacimiento de Torralba se encuentra en el valle del río Mansegar, en una posición encajada en la terraza de $+35 \mathrm{~m}$ de este río. Toda la secuencia de terrazas del Mansegar se construyó a partir de la Superficie de Ambrona (según Pérez-González et al. 2005).

equiparable, de 220 y $240 \mathrm{ka} U$ series (Howell et al. 1995). Este conjunto de fechas demuestra que los yacimientos no son contemporáneos, dibujando una secuencia de ocupaciones. Torralba, en el fondo de valle del río Mansegar, quedaría situado hacia el MIS 7. En cambio las unidades estratigráficas inferior y media de Ambrona corresponderían respectivamente al MIS 11 y al MIS 10 ó 9, en posiciones relacionadas con la red de drenaje y las pequeñas charcas, que se sucedieron en el fondo del poljé de Conquezuela.

El conocimiento estratigráfico actual sobre Torralba no es tan completo como el de Ambrona (Pérez-González et al. 2005). Las formaciones más antiguas sobre las que se asientan los depósitos pleistocenos de Torralba, como sucede en Ambrona, están formadas por las arcillas rojas y yesos del Keuper y las más recientes carbonatadas de edad Triásico-Jurásico (Bascones y Martínez 1981). A pesar de la gran extensión del yacimien- en el sector oeste del área excavada (Figs. 1 y 3). Es un perfil estratigráfico compuesto que comienza con facies coluvionares rojas (red colluvium) apoyadas sobre el Keuper, con un espesor mayor de 3-4 m. Estos depósitos desaparecen hacia el Norte. La secuencia continúa con arenas grises en las que se intercalan facies de gravas angulosas y subangulosas de composición carbonatada, con tamaños de 1-3 cm de eje mayor. Su espesor máximo, $1 \mathrm{~m}$, se alcanza en la mitad septentrional del perfil. En este sector del yacimiento los niveles pleistocenos, al igual que el Keuper, están afectados por fallas inversas con desplazamientos superiores al metro. En estas facies fluviales de gravas y arenas se situaban las principales concentraciones de fauna e industria registradas en las excavaciones de F. C. Howell.

A techo se sitúa una unidad muy continua de marga gris-verdosa, algo más arenosa en la base, con potencia máxima de unos $2 \mathrm{~m}$. Sobre esas facies, de carácter lacustre somero, todavía se superpone un depósito aluvionar-coluvionar rojo (red alluvium) entre 0 y 1,5 m de espesor conservado.

En el primer sector excavado en la parte oriental del yacimiento por el marqués de Cerralbo en 1909-1911 (Fig. 1) Pedro Palacios describió una sección de $4 \mathrm{~m}$ de potencia en la que diferenciaba 6 unidades. A muro señalaba dos niveles, uno con aglomerados y otro de brechas de cantos carbonatados a los que seguirían tres horizontes de margas grises, muy rico el inferior en grava fina carbonatada, finalizando con otro aglomerado de clastos de grava de color rojizo (10). La co-

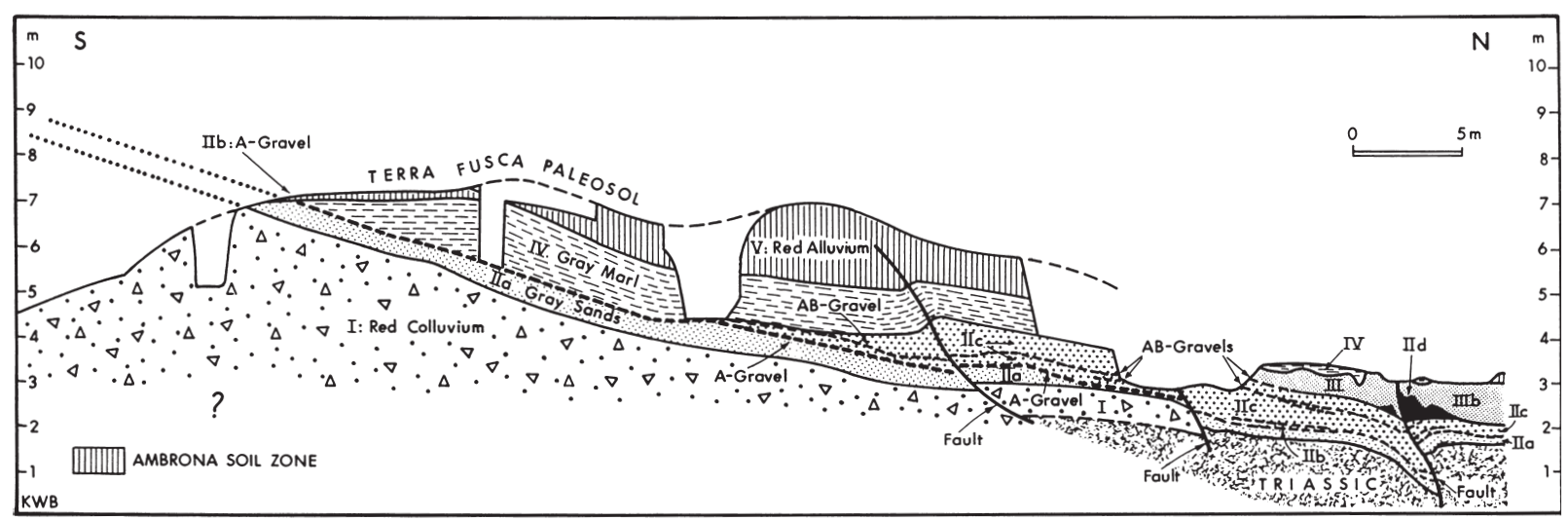

Fig. 3. Perfil estratigráfico compuesto de Torralba (modificado de Butzer 1965).

to la única estratigrafía de detalle es la sección N-S publicada por K. W. Butzer (1965), levantada

(10) Véase n. 2, p. 201. 
rrelación de términos entre los depósitos descritos por Palacios y por Butzer no es muy evidente, pero parece probable que los aglomerados y brechas basales puedan corresponderse con el red colluvium de Butzer. Las margas grises con gravas finas representarían entonces las facies fluviales, mientras que la marga gris a techo puede ser equivalente a la marga gris, y el aglomerado calizo con matriz rojiza sería el depósito coluvionar-aluvionar rojo que erosionaría la secuencia en todo el yacimiento. La industria y la fauna tanto de las excavaciones del marqués de Cerralbo como de Howell se localizan en los términos fluviales, los cuales pueden estar asociados a capas arcillosas de llanura de inundación.

\section{ESTUDIO DE LA INDUSTRIA}

\subsection{Metodología y objetivos del estudio}

Presentamos a continuación el primer estudio tecnológico detallado realizado sobre la totalidad de las series industriales conservadas en el Museo Numantino de Soria, Museo Nacional de Ciencias Naturales y Museo Arqueológico Nacional procedentes de las excavaciones del marqués de Cerralbo y Howell en Torralba. En nuestro análisis utilizamos términos tipológicos clásicos (Bordes 1961), si bien estructurados en torno a la noción tecno-económica de cadena operativa, conforme a conceptos básicos definidos para el Paleolítico antiguo europeo (Boëda et al. 1990; Inizan et al. 1995). Incorporamos también aportaciones efectuadas en los últimos años (Bourguignon 1998; Tixier y Turq 1999; Turq 2000; Boëda 2001; Mourre 2003; Bourguignon et al. 2004).

La desconocida posición estratigráfica de las series estudiadas limita la aplicación de esta metodología, en especial la interpretación de los resultados, puesto que los materiales no son estrictamente sincrónicos y se integran para su estudio en el marco teórico de una cadena operativa. La situación sería equivalente, aún conociendo la procedencia estratigráfica, puesto que no estaríamos ante elementos registrados en posiciones autóctonas que pudieran integrarse en procesos unitarios de gestión. La posible excepción es la pequeña parte de la industria procedente de margas acumuladas en procesos de nula o baja energía. La mayor parte de la industria de Torralba procede de unidades fluviales más o menos tractivas, medios que pudieron determinar desplazamientos, selecciones por forma, peso y tamaño y reorganizaciones de intensidad variable. Tales fenómenos impiden aceptarlas a priori como conjuntos homogéneos.

La procedencia de la industria, depósitos fluviales situados en secuencia estratigráfica, implica en todo caso proximidad temporal. En estas circunstancias aplicamos la noción de cadena operativa para intentar reconocer y alcanzar conclusiones respecto a la importancia relativa de las distintas fases de gestión tecnológica representadas en el yacimiento. Este planteamiento permite acumular en el estudio ambas colecciones, que proceden de las mismas unidades estratigráficas, siempre teniendo en cuenta que los distintos métodos de excavación aplicados por el marqués de Cerralbo y Howell dieron lugar, como comprobaremos, a sesgos notables y diferenciados. Por ello partimos de un primer examen independiente de cada serie para después valorarlas en conjunto en la discusión.

Seguiremos en los estudios tecnológicos respectivos el orden derivado de las etapas comprendidas entre la fase inicial de captación de materias primas y las fases finales de mantenimiento y abandono, pasando por las etapas de producción. A partir de los resultados obtenidos pretendemos discutir el nivel de representatividad de estos conjuntos en el marco de las intervenciones realizadas y proponer conclusiones acerca de la gestión de las materias primas, la naturaleza tecnológica de la industria y la intensidad de la actividad humana en Torralba. Nuestro objetivo final es contrastar si estamos ante conjuntos industriales achelenses, como habitualmente se viene considerando, o si es posible detectar elementos extraños a dicho tecnocomplejo, situación que permitiría introducir matices o plantear una interpretación alternativa.

\subsection{Composición básica de las series estudiadas}

La estructura de la colección desde la perspectiva de la cadena operativa (Tab. 1) acusa discontinuidades marcadas que pueden responder

Trab. Prehist., 72, N. ${ }^{\circ}$ 1, enero-junio 2015, pp. 41-63, ISSN: 0082-5638

doi: $10.3989 /$ tp. 2015.12143 


\begin{tabular}{|c|c|c|c|c|c|c|c|}
\hline & & \multicolumn{3}{|c|}{ Colección marqués de Cerralbo } & \multicolumn{3}{|c|}{ Colección Howell } \\
\hline & & $\begin{array}{l}\text { Elementos } \\
\text { brutos }\end{array}$ & Utensilios & Total & $\begin{array}{l}\text { Elementos } \\
\text { brutos }\end{array}$ & Utensilios & Total \\
\hline \multicolumn{8}{|c|}{ 0. Adquisición } \\
\hline 0.1 & Cantos, percutores & 25 & - & 25 & 29 & 6 & 35 \\
\hline 0.2 & Cantos probados & - & - & 0 & - & - & 0 \\
\hline 0.3 & Desprendimientos & - & - & 0 & - & - & 0 \\
\hline \multicolumn{2}{|r|}{ Subtotal adquisición } & 25 & $\mathbf{0}$ & 25 & 29 & 6 & 35 \\
\hline \multicolumn{8}{|c|}{ 1. Decorticado } \\
\hline 1.1 & Lascas corticales $(>90 \%)$ & 5 & - & 5 & 11 & 3 & 14 \\
\hline 1.2 & Lascas muy corticales $(90 / 50 \%)$ & - & - & 0 & - & - & 0 \\
\hline 1.3 & Fragmentos de lasca cortical & - & - & 0 & - & - & 0 \\
\hline \multicolumn{8}{|c|}{ 2. Productos ordinarios } \\
\hline 2.1 & Lascas y FL no corticales $(<10 \%)$ & 60 & 119 & 179 & 318 & 163 & 481 \\
\hline 2.2 & Lascas y FL con restos cort. $(50 / 10 \%)$ & 22 & 66 & 88 & 85 & 75 & 160 \\
\hline 2.3 & Lascas y FL Jano & 1 & 5 & 6 & 2 & 3 & 5 \\
\hline \multicolumn{8}{|c|}{ 3. Productos con dorso } \\
\hline 3.1 & Lascas y FL con dorso desbordante & 15 & 13 & 28 & 7 & 11 & 18 \\
\hline 3.2 & Lascas y FL con dorso natural & - & - & 0 & 2 & 0 & 2 \\
\hline 3.3 & Puntas seudo-levallois & 4 & 1 & 5 & 1 & 1 & 2 \\
\hline \multicolumn{8}{|c|}{ 4. Productos levallois } \\
\hline 4.1 & Lascas levallois & - & - & 0 & - & - & 0 \\
\hline 4.2 & Puntas levallois & - & - & 0 & - & - & 0 \\
\hline \multicolumn{8}{|c|}{ 5. Núcleos } \\
\hline 5.1 & Núcleos sobre canto & 25 & 3 & 28 & 26 & - & 26 \\
\hline 5.2 & Núcleos sobre lasca & 9 & 1 & 10 & 7 & 4 & 11 \\
\hline 5.3 & Núcleos en soporte indiferenciado & 21 & 2 & 23 & 26 & - & 26 \\
\hline 5.4 & Chunks & 4 & - & 4 & 16 & - & 16 \\
\hline \multicolumn{8}{|c|}{ 6. Productos secundarios } \\
\hline 6.1 & $\begin{array}{l}\text { Lascas procedentes del reavivado de utensilios } \\
\text { retocados }\end{array}$ & - & - & 0 & - & - & 0 \\
\hline & Subtotal producción & 166 & 210 & 376 & 501 & 260 & 761 \\
\hline \multicolumn{8}{|c|}{ 7. Utensilios conformados } \\
\hline 7.1 & Bifaces + hendedores + picos & - & $\begin{array}{c}(118+4) / \\
20 / 0\end{array}$ & 142 & & $60 / 12 / 2$ & 74 \\
\hline 7.2 & Lascas procedentes de configuración bifacial & 5 & - & 5 & 1 & - & 1 \\
\hline 7.3 & Cantos tallados & - & 2 & 2 & - & 2 & 2 \\
\hline 7.4 & Otros configurados s/canto & - & 2 & 2 & - & - & 0 \\
\hline & Subtotal conformación & 5 & 146 & 151 & 1 & 76 & 77 \\
\hline \multicolumn{8}{|c|}{ 8. Productos menores no específicos $(<10 \mathrm{~mm})$} \\
\hline 8.1 & Esquirlas y pequeñas lascas y fragmentos & - & - & 0 & 104 & - & 104 \\
\hline & Subtotal pmne & $\mathbf{0}$ & $\mathbf{0}$ & $\mathbf{0}$ & 104 & $\mathbf{0}$ & 104 \\
\hline & TOTALES & 196 & 356 & 552 & 635 & 342 & 977 \\
\hline
\end{tabular}

Tab. 1. Torralba (Soria). Colecciones marqués de Cerralbo y Howell. Composición tecnológica global. 
en buena medida a los métodos de excavación. Eso parece indicar el elevado porcentaje de lascas retocadas, anómalamente superior al de no retocadas. También el de configurados achelenses (bifaces, hendedores y picos), que constituye más de la cuarta parte del total de la serie. La falta de productos menores también resulta sintomática. En contraposición la colección Howell (Tab. 1) sí los incluye y ofrece una proporción algo más equilibrada entre lascas en bruto y retocadas (2:1), una presencia de configurados achelenses menos llamativa $(8,5 \%)$ y una compensación mayor entre núcleos y lascas (chunks y productos menores excluidos), 1:11 o 1:5 si incluimos en la correlación todos los configurados. Estas dos últimas proporciones en la colección del marqués de Cerralbo se reducían a 1:5 y 1:1.5 respectivamente. La segunda resulta especialmente desequilibrada, ya que nos indicaría un palpable déficit de productos, solamente tres por cada dos soportes tallados.

En ambas series se emplean las mismas rocas, calizas, sílex, cuarcitas y cuarzo (Tab. 2), aunque en diferentes proporciones. El sílex representa algo más de la mitad de la industria en ambas colecciones. Le siguen cuarcitas y calizas, si bien la diferencia entre ambas es notable y mutuamente compensada. En la del marqués de Cerralbo hay un 14\% más de caliza y en la de Howell se da una diferencia semejante a favor de la cuarcita. El recurso al cuarzo es muy limitado, en especial en la primera.

La superficie de las piezas muestra una ausencia casi total de filos y aristas frescos en los dos conjuntos, algo esperable en procedencias de depósitos fluviales. En cerca del 80\% de ambas series las huellas de rodamiento son observables a simple vista. El desgaste en las piezas de caliza es más intenso, en relación con

\begin{tabular}{|l|c|c|}
\hline $\begin{array}{c}\text { Materias } \\
\text { Primas }\end{array}$ & $\begin{array}{c}\text { Colección } \\
\text { Cerralbo (\%) }\end{array}$ & $\begin{array}{c}\text { Colección } \\
\text { Howell (\%) }\end{array}$ \\
\hline Caliza & $140(25,4)$ & $108(11,1)$ \\
\hline Cuarcita & $115(20,8)$ & $337(34,5)$ \\
\hline Cuarzo & $2(0,4)$ & $16(1,6)$ \\
\hline Sílex & $295(53,4)$ & $516(52,8)$ \\
\hline TOTAL & $\mathbf{5 5 2}$ & $\mathbf{9 7 7}$ \\
\hline
\end{tabular}

Tab. 2. Torralba. Materias primas de la industria lítica. su mayor fragilidad frente al sílex y cuarcita, rocas de mayor dureza.

\subsection{Estudio de la colección del marqués de Cerralbo}

\subsubsection{Fase de captación}

La fase de captación carece de elementos en cuarcita o en sílex y no está claramente representada en la serie. Hipotéticamente hemos adscrito a esta fase 25 cantos calcáreos sin estigmas de talla, valorando exclusivamente su tamaño superior a los clastos naturales de los niveles de procedencia (Tab. 3). El marqués de Cerralbo pudo conservarlos atendiendo a una morfología especial que hiciera pensar en su introducción intencionada en el yacimiento para algún uso esporádico.

La ausencia de elementos en materias primas con procedencia de zonas alejadas del yacimiento contrasta con lo observado en la colección Howell y también en paleoambientes próximos comparables, como la unidad estratigráfica inferior de Ambrona (Santonja y Pérez-González 2001). En ambos casos es clara la introducción de cantos de cuarcita en bruto y su uso como percutores. Ello sugiere que su falta en la colección del marqués Cerralbo es una anomalía. Es posible que descartara este tipo de piezas.

\begin{tabular}{|c|c|c|c|c|c|c|}
\hline Colección & $\begin{array}{c}\text { Materia } \\
\text { prima }\end{array}$ & $\mathbf{N}$ & $\mathbf{L}$ & $\mathbf{A}$ & $\mathbf{E}$ & Observaciones \\
\hline $\begin{array}{l}\text { Marqués } \\
\text { de } \\
\text { Cerralbo }\end{array}$ & Caliza & 25 & 83 & 59 & 32 & $\begin{array}{l}\text { Cantos sin } \\
\text { estigmas } \\
\text { de talla o } \\
\text { utilización }\end{array}$ \\
\hline \multirow{5}{*}{ Howell } & Caliza & 7 & 87 & 69 & 46 & \multirow{3}{*}{$\begin{array}{l}\text { Cantos sin } \\
\text { estigmas } \\
\text { de talla o } \\
\text { utilización }\end{array}$} \\
\hline & Cuarcita & 20 & 52 & 61 & 41 & \\
\hline & Cuarzo & 2 & 34 & 36 & 30 & \\
\hline & Caliza & 1 & 110 & 63 & 45 & \multirow{2}{*}{$\begin{array}{l}\text { Cantos con } \\
\text { estigmas } \\
\text { de talla o } \\
\text { utilización }\end{array}$} \\
\hline & Cuarcita & 5 & 72 & 79 & 54 & \\
\hline
\end{tabular}

Tab. 3. Torralba. Materia prima y dimensiones medias $(\mathrm{mm})$ de longitud (L), anchura (A) y espesor (E) de los cantos incluidos en la fase de captación (piezas completas)

Trab. Prehist., 72, N. ${ }^{\circ}$ 1, enero-junio 2015, pp. 41-63, ISSN: 0082-5638

doi: $10.3989 /$ tp.2015.12143 


\subsubsection{Fase de producción}

Un total de 376 piezas (Tab. 1), que representan el 68,1\% del total, se adscriben inicialmente a la fase de producción: 311 lascas y fragmentos de todas las categorías, 65 núcleos y 4 chunks. Insistimos de nuevo sobre la ausencia de esquirlas, cuyo reconocimiento sería prácticamente imposible con los sistemas de excavación de la época.

Los productos de lascado están integrados fundamentalmente por lascas ordinarias, de tendencia cuadrangular, con unas dimensiones medias de 51 x 46 x $16 \mathrm{~mm}$. La mayoría son de sílex (64,3\%) y cuarcita $(23,8 \%)$. Además hay 35 piezas calizas $(11,2 \%)$ y 2 de cuarzo $(0,6 \%)$. Predominan de forma neta las lascas no corticales o parcialmente corticales, mientras que sólo se han visto 5 lascas con todo su anverso cortical. Hay un componente interesante de puntas seudolevallois y lascas desbordantes, mientras que es curiosa la falta de alguna con dorso natural. Ninguna de las 6 lascas obtenidas a partir de la superficie ventral de lascas-soporte responde en sentido estricto a un método kombewa (extracciones únicas o aisladas en una cara bulbar), ya que todas ellas presentan restos de varios negativos en la superficie más antigua. Ello no permite descartar su origen en la conformación de hendedores o bifaces sobre lasca.

No se han observado lascas de reavivado de utensilios retocados, que podría constituir una característica tecnológica a tener en cuenta. Los únicos productos de acondicionamiento de superficies de extracción reconocidos con nitidez son 28 lascas desbordantes, derivadas probablemente de núcleos discoides. Otros productos característicos serían 5 puntas seudolevallois. No hay lascas con morfología levallois clara. Los talones, con una primacía clara de morfologías lisas, y minoritariamente diedros $(11,3 \%)$, facetados $(6,5 \%)$ y lineales $(2,1 \%)$, hablan de una preparación somera y discontinua de los planos de percusión en los núcleos.

En el macroutillaje se registran al menos 43 piezas, entre hendedores y bifaces, configurados a partir de lascas. Las dimensiones máximas de estos soportes $(192 \times 51 \times 73 \mathrm{~mm})$, incluso las medias (125 x $82 \times 39 \mathrm{~mm})$, sobrepasan con creces las del lascado antes descrito (Tab. 4) y las de los negativos observados en los núcleos de la serie, de los que obviamente no pueden proceder.

\begin{tabular}{|c|c|c|c|c|c|c|}
\hline \multirow{2}{*}{$\begin{array}{c}\text { Medidas } \\
\text { en mm }\end{array}$} & \multicolumn{2}{|c|}{$\begin{array}{c}\text { Colección marqués } \\
\text { de Cerralbo }\end{array}$} & \multicolumn{3}{|c|}{ Colección Howell } \\
\cline { 2 - 7 } & $\begin{array}{c}\text { Lon- } \\
\text { gitud }\end{array}$ & $\begin{array}{c}\text { An- } \\
\text { chura }\end{array}$ & $\begin{array}{c}\text { Espe- } \\
\text { sor }\end{array}$ & $\begin{array}{c}\text { Lon- } \\
\text { gitud }\end{array}$ & $\begin{array}{c}\text { An- } \\
\text { chura }\end{array}$ & $\begin{array}{c}\text { Espe- } \\
\text { sor }\end{array}$ \\
\hline $\begin{array}{c}\text { Productos. } \\
\text { Valores } \\
\text { medios }\end{array}$ & 51 & 46 & 16 & 35 & 35 & 16 \\
\hline $\begin{array}{c}\text { Macroutillaje. } \\
\text { Valores } \\
\text { medios }\end{array}$ & 125 & 82 & 39 & 121 & 70 & 36 \\
\hline $\begin{array}{c}\text { Macroutillaje. } \\
\text { Valores } \\
\text { máximos }\end{array}$ & 218 & 151 & 73 & 186 & 126 & 67 \\
\hline
\end{tabular}

Tab 4. Dimensiones (mm) medias de las lascas completas y dimensiones medias y máximas del macroutillaje (piezas completas) de las colecciones marqués de Cerralbo y Howell.

Se han identificado 61 núcleos, casi la mitad de sílex, seguidos de otros de caliza (34\%) y cuarcita $(18 \%)$. Los soportes mayoritarios identificados son cantos rodados, nódulos de sílex y cantos angulosos calcáreos. Hay 10 núcleos sobre lasca, un porcentaje notable. La explotación fue en general muy intensa, especialmente en los soportes en materias primas de mayor calidad. Hay 22 ejemplares completamente agotados, en 9 de los cuales no es identificable el método de explotación. La explotación de los cantos calizos es más somera a través de esquemas elementales, con grados de aprovechamiento reducidos.

Igualmente se observan diferencias en los sistemas de explotación en función de las materias primas. Los 9 cantos y placas calizas fueron mayoritariamente explotados siguiendo esquemas elementales o muy elementales: una o dos extracciones aisladas o series de hasta tres extracciones que parten de planos de percusión sin preparar. Esquemas simples -no extracciones únicas kombewa sensu stricto- se aplicaron también en la explotación de las superficies ventrales de 6 lascas.

En los soportes en sílex y cuarcita se aplicaron con frecuencia esquemas multipolares y discoides. Hasta 18 piezas muestran un esquema multifacial, con un alto número de extracciones organizadas en tres o más superficies, respondiendo a estrategias de extracción rotatorias.

Hay 12 núcleos con explotación centrípeta (Fig. 4: 6 y 11): 8 de sílex, 1 de cuarcita y 2 de 

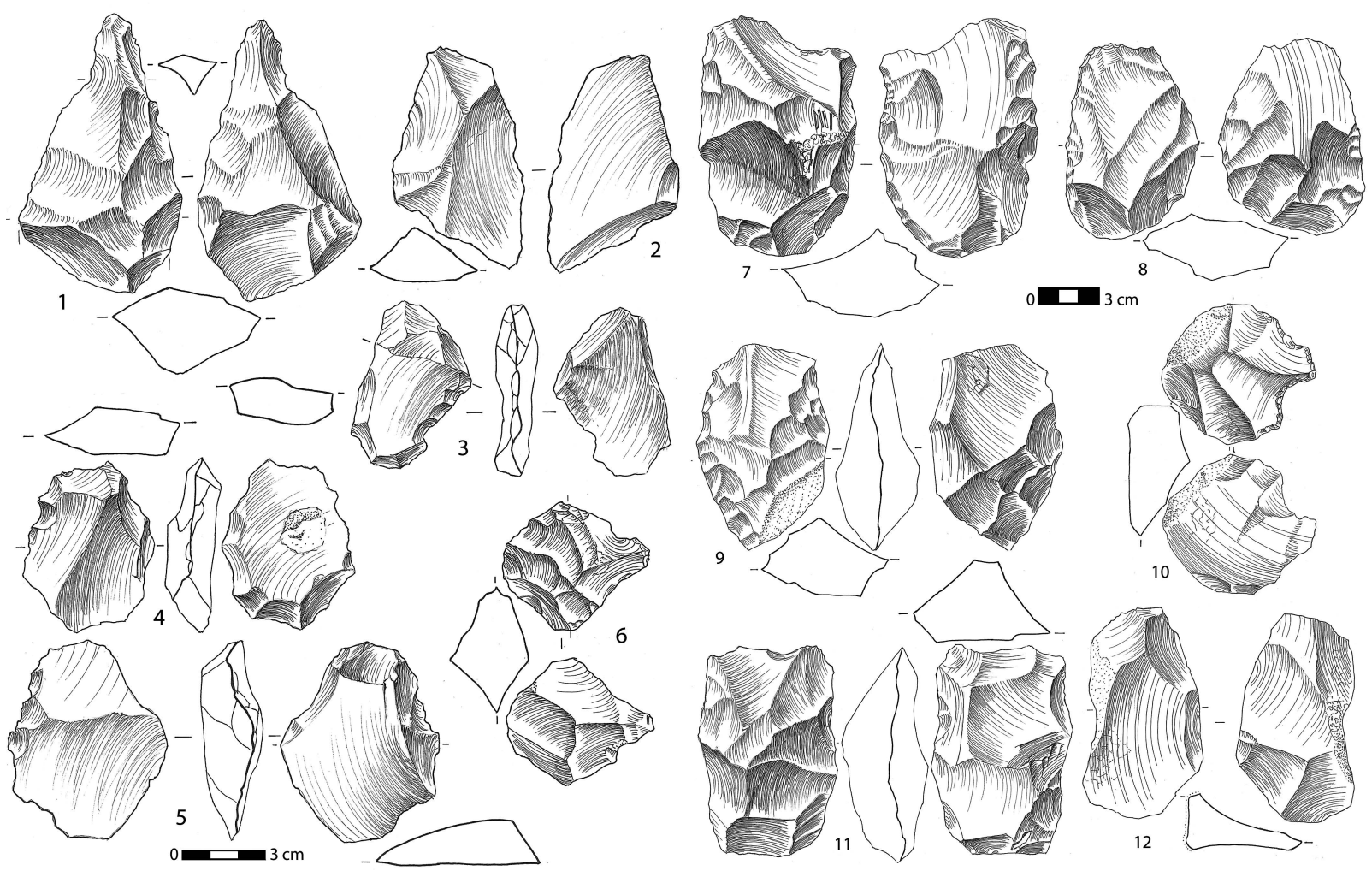

Fig. 4. Torralba: 1. punta de bifaz; 2-5 lascas de talla de bifaz (3 retocada en denticulado); 6 núcleo discoidal bifacial; 7-9 hendedores de tipo II: 7 reavivado y con retoque de raedera inversa en el lado derecho; 8 con retoque somero en el filo; 11 con retalla inversa importante para mantenimiento del filo; 9 bifaz de filo transversal, conseguido mediante coup de tranchet inverso; 10 raedera cóncava doble más raspador atípico en un núcleo discoidal parcial sobre lasca; 12 núcleo bifacial. Colecciones marqués de Cerralbo (1-11) y Howell (12). Sílex.

caliza. Con unas dimensiones medias de 58 x 59 x $60 \mathrm{~mm}$, algunos presentan superficies jerarquizadas de explotación y de percusión. Estas en general son periféricas - no invasoras-y parciales. Dos núcleos podrían responder a una concepción levallois inicial, si bien habrían sido explotados otra vez con esquemas discoidales. Uno muestra restos de una posible extracción preferencial muy recortada en un plano horizontal. Otro de pequeño tamaño $(38 \times 31 \times 20 \mathrm{~mm})$, con configuración periférica, está intensamente explotado según un esquema recurrente centrípeto, con restos de cuatro negativos en un plano horizontal. En todos los demás la explotación es de clara tendencia centrípeta en planos tangenciales, mostrando entre 13 y 4 negativos. La intensa explotación de los núcleos se observa también en un ejemplar bifacial de cuarcita $(64 \times 53 \times 27 \mathrm{~mm})$ con restos de 32 negativos.

\subsubsection{Fase de consumo}

La mayoría de la colección del marqués de Cerralbo está constituida por elementos transformados mediante retoque. El grupo está integrado por utensilios sobre lasca (204) y otras piezas de tamaño y morfología comparable elaboradas sobre núcleos en avanzado estado de explotación (6) o sobre cantos (2). El macroutillaje achelense conformado cuenta con menos ejemplares, pero es el componente más llamativo de esta colección. Comprende 122 bifaces y 20 hendedores, a los que cabe sumar un par de cantos tallados (Tab. 1).

El peso de esta fase en la colección del marqués de Cerralbo, 356 piezas (64,5\% del total), es tan elevado para lo habitual en conjuntos del Paleolítico antiguo al aire libre, que es imprescindible considerarlo resultado de una conservación selectiva. 
El primer gran grupo que se reconoce en esta fase comprende el utillaje retocado sobre lasca (204 piezas), sobre pequeños cantos (2) y en núcleos agotados (6 piezas), que marcan una leve tendencia a la ramificación de la cadena operativa. Se observa un uso diferenciado de las materias primas. La más empleada fue el sílex, $72,2 \%$, porcentaje que en las lascas no retocadas se reduce al 48,9\%. Las lascas de caliza retocadas no llegan al $10 \%$ y las no retocadas alcanzan el $16 \%$. En cuarcita se observa una tendencia similar: son el $17,6 \%$ de los utensilios sobre lasca y el 34\% de las lascas no retocadas. El tipo y formato de lasca por lo general es no cortical, de dimensiones muy ligeramente superiores a las lascas no retocadas, lo que implicaría una leve tendencia a seleccionar los soportes mayores (Tab. 5).

La intensidad del retoque suele ser limitada, aunque a veces llega a penetrar y puede formar ángulos casi rectos, produciendo frentes retocados abruptos o semiabruptos. En ocasiones se observan secuencias repetidas de retoque que dan lugar a frentes escaleriformes. Implican actividades de reavivado o mantenimiento que deben haber producido lascas características de pequeño tamaño que no se han conservado. El patrón normal de retoque es de carácter simple, directo, y sin excesiva modificación de los filos de la lasca soporte.

Tipológicamente priman las raederas sobre lasca: un total de 118 (55,7\% del conjunto de retocados). Suelen ser raederas laterales simples (49) y transversales (28). Junto a ellas una gran variedad de raederas dobles (12), con dorso adelgazado (7), alternas (5), sobre cara plana (4), bifaciales (4), convergentes (4), desviadas (3) y con retoque abrupto (2) (Fig. 5: 1). Hay 6 núcleos que se retocaron creando utensilios afines a las raederas (Figs. 5: 5 y 3), con tamaños comparables con las elaboradas sobre lasca. También 2 cantos de cuar-

\begin{tabular}{|c|c|c|c|c|c|c|}
\hline \multirow{2}{*}{} & \multicolumn{3}{|c|}{ Útiles sobre lasca } & \multicolumn{3}{c|}{ Lascas sin retocar } \\
\cline { 2 - 7 } & Mín. & Máx. & Md & Mín. & Máx. & Md \\
\hline L & 18 & 168 & $\mathbf{5 2 , 0 2}$ & 13 & 168 & $\mathbf{5 1 , 1 2}$ \\
\hline A & 15 & 112 & $\mathbf{4 7 , 1 2}$ & 15 & 117 & $\mathbf{4 6 , 1 5}$ \\
\hline E & 4 & 52 & $\mathbf{1 7 , 6 0}$ & 3 & 45 & $\mathbf{1 6 , 7 8}$ \\
\hline
\end{tabular}

Tab. 5. Comparativa de dimensiones ( $\mathrm{mm})$ entre lascas retocadas y sin retocar en la colección marqués de Cerralbo.

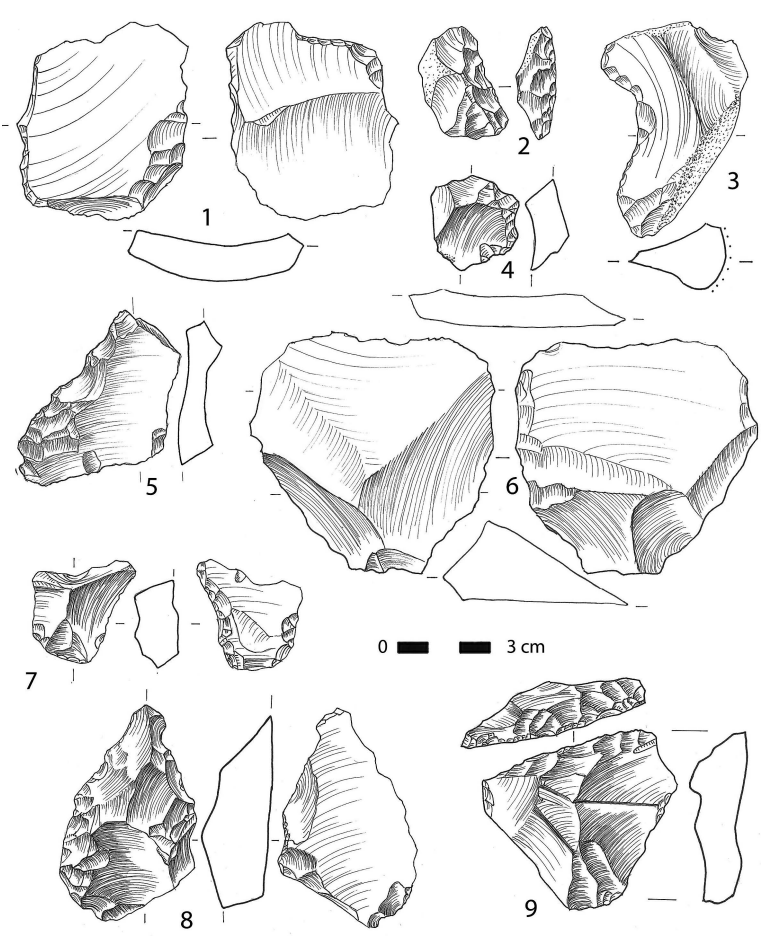

Fig. 5. Torralba. Utensilios sobre lasca de sílex: 1 raedera con retoque abrupto; 2 raedera cóncava; 3 raedera cóncava sobre núcleo; 4 raspador atípico; 5 denticulado; 6 tranchet; 7 raedera inversa doble sobre punta seudolevallois; 8 raedera convergente; 9 raedera transversal semi-Quina. Colecciones marqués de Cerralbo (1, 3 y 6) y Howell $(2,4-5,7-9)$.

cita, uno de tamaño grande (132 x $103 \times 61 \mathrm{~mm})$, recibieron retoque de raedera en un borde.

En número inferior, se registran también denticulados y lascas con un retoque somero (46), insuficiente para configurar una raedera o un denticulado. Destacan algunos instrumentos de carácter progresivo como raspadores netos (4) y otros más atípicos (3), además de un tranchet bien definido (Fig. 5: 6) y utensilios compuestos (8), que combinan frentes de raedera con otros denticulados, o bien perforadores o becs (Tab. 6).

Como ya se ha destacado, el utillaje conformado de carácter achelense $(26,1 \%)$ es el conjunto más significativo de la colección del marqués de Cerralbo. Comprende fundamentalmente bifaces (122, incluyendo 4 fragmentos) y un número significativo de hendedores (20, 1:6 respecto a los bifaces) y piezas afines (2). Asimilamos 2 cantos con talla amplia a los conformados no achelen- 


\begin{tabular}{|c|c|c|c|c|}
\hline \multirow[t]{2}{*}{$\begin{array}{l}\text { Tipo de } \\
\text { utensilio }\end{array}$} & \multicolumn{2}{|c|}{$\begin{array}{c}\text { Colección } \\
\text { marqués } \\
\text { de Cerralbo }\end{array}$} & \multicolumn{2}{|c|}{$\begin{array}{c}\text { Colección } \\
\text { Howell }\end{array}$} \\
\hline & $\mathbf{N}$ & $\%$ & $\mathbf{N}$ & $\%$ \\
\hline Lascas retocadas & 46 & 21,7 & 84 & 32,3 \\
\hline Raederas simples & 49 & 23,1 & 39 & 15,0 \\
\hline $\begin{array}{l}\text { Raederas } \\
\text { transversales }\end{array}$ & 28 & 13,2 & 41 & 15,8 \\
\hline Raederas inversas & 4 & 1,9 & 13 & 5,0 \\
\hline $\begin{array}{l}\text { Raederas } \\
\text { bifaciales }\end{array}$ & 4 & 1,9 & 3 & 1,2 \\
\hline $\begin{array}{l}\text { Raederas con } \\
\text { retoque abrupto }\end{array}$ & 2 & 0,9 & 5 & 1,9 \\
\hline Raederas dobles & 12 & 5,7 & 6 & 2,3 \\
\hline Raederas alternas & 5 & 2,4 & 3 & 1,2 \\
\hline $\begin{array}{l}\text { Raederas con } \\
\text { dorso adelgazado }\end{array}$ & 7 & 3,3 & 5 & 1,9 \\
\hline $\begin{array}{l}\text { Raederas } \\
\text { convergentes }\end{array}$ & 4 & 1,9 & 9 & 3,5 \\
\hline $\begin{array}{l}\text { Raederas } \\
\text { desviadas }\end{array}$ & 3 & 1,4 & 1 & 0,4 \\
\hline $\begin{array}{l}\text { Raederas s/ } \\
\text { núcleo }\end{array}$ & 6 & 2,8 & 3 & 1,2 \\
\hline Raederas s/canto & 2 & 0,9 & 0 & 0 \\
\hline Denticulados & 12 & 5,7 & 20 & 7,7 \\
\hline Puntas de Tayac & 1 & 0,5 & 1 & 0,4 \\
\hline Escotaduras & 6 & 2,8 & 8 & 3,1 \\
\hline Becs & 2 & 0,9 & 3 & 1,2 \\
\hline Perforadores & 1 & 0,5 & 3 & 1,2 \\
\hline Raspadores & 4 & 2,0 & 0 & 0 \\
\hline $\begin{array}{l}\text { Raspadores } \\
\text { atípicos }\end{array}$ & 3 & 1,4 & 3 & 1,2 \\
\hline Tranchet & 1 & 0,5 & 0 & 0 \\
\hline Rabot o cepillos & 1 & 0,5 & 0 & 0 \\
\hline $\begin{array}{l}\text { Útiles } \\
\text { compuestos }\end{array}$ & 8 & 3,8 & 7 & 2,7 \\
\hline $\begin{array}{l}\text { Fragmentos de } \\
\text { utensilio }\end{array}$ & 1 & 0,5 & 3 & 1,2 \\
\hline Total & 212 & 100,2 & 260 & 100,4 \\
\hline
\end{tabular}

Tab. 6. Clasificación de los útiles retocados de Torralba (conceptos tipológicos según Bordes 1961) ses, aunque su naturaleza como utensilios no sea totalmente evidente.

La utilización de caliza compacta local es particularmente significativa en los bifaces (en 52). De manera equivalente se recurrió al sílex (46), mientras el uso de cuarcita fue más reducido (24). Los bifaces oscilan entre 45 y $218 \mathrm{~mm}$ de longitud, 34 y $151 \mathrm{~mm}$ e anchura y 17 y $73 \mathrm{~mm}$ de espesor. El equilibrio formal de estas piezas y en especial la relación espesor/anchura (Fig. 6), está determinado en gran medida por los soportes empleados, ya que la reducción no suele ser tan intensa como para modificar sus volúmenes por completo. Cuando el soporte es una lasca (26) se consiguen piezas menos gruesas, con relaciones mayores entre anchura y espesor. Otros soportes identificables son nódulos de sílex (12), placas calizas (20) y cantos rodados de caliza (10) y cuarcita (10).

Predomina la talla mediante percutor duro, con una intensidad que parece variar en función de la materia prima. A veces se observan regularizaciones finales producidas con percutor blando. La intensidad de talla es más alta en los soportes de mayor calidad -sílex y cuarcita- hasta con 26 extracciones por superficie. La talla de placas y cantos calizos es más somera. Cumple de manera elemental el objetivo de conseguir un equilibrio bilateral y en menor medida bifacial.

Entre las piezas con morfología mejor definida predominan las formas espesas de tendencia apuntada: amigdaloide (Figs. 7: 5 y 7) y lanceolada (Fig. 7: 4). Las siluetas ovalares también son frecuentes, y en menor medida las elípticas o limandes (Bordes 1961). Es muy significativa la presencia de bifaces de filo transversal, cuyos equilibrios formales enlazan además con los de los hendedores. De hecho hay una clara transferencia entre ambos conceptos de conformación: hendedores con filos reavivados y bifaces sobre lasca con filos obtenidos mediante coup de tranchet con proporciones equiparables (Fig. 4: 9). Los bifaces más planos (16), con $\mathrm{m} / \mathrm{e}>2.35$ (Fig. 6) están casi siempre elaborados a partir de lasca, por lo que esta proporción es propia del soporte y no viene determinada por la reducción bifacial. Al margen de estas formas más regulares se registra un alto porcentaje de bifaces nucleiformes (9), y parciales o en proceso de elaboración (45), más del $60 \%$ de ellos sobre soportes calizos. En estos casos la configuración tanto bifacial

Trab. Prehist., 72, N. ${ }^{\circ}$ 1, enero-junio 2015, pp. 41-63, ISSN: 0082-5638

doi: $10.3989 /$ tp. 2015.12143 

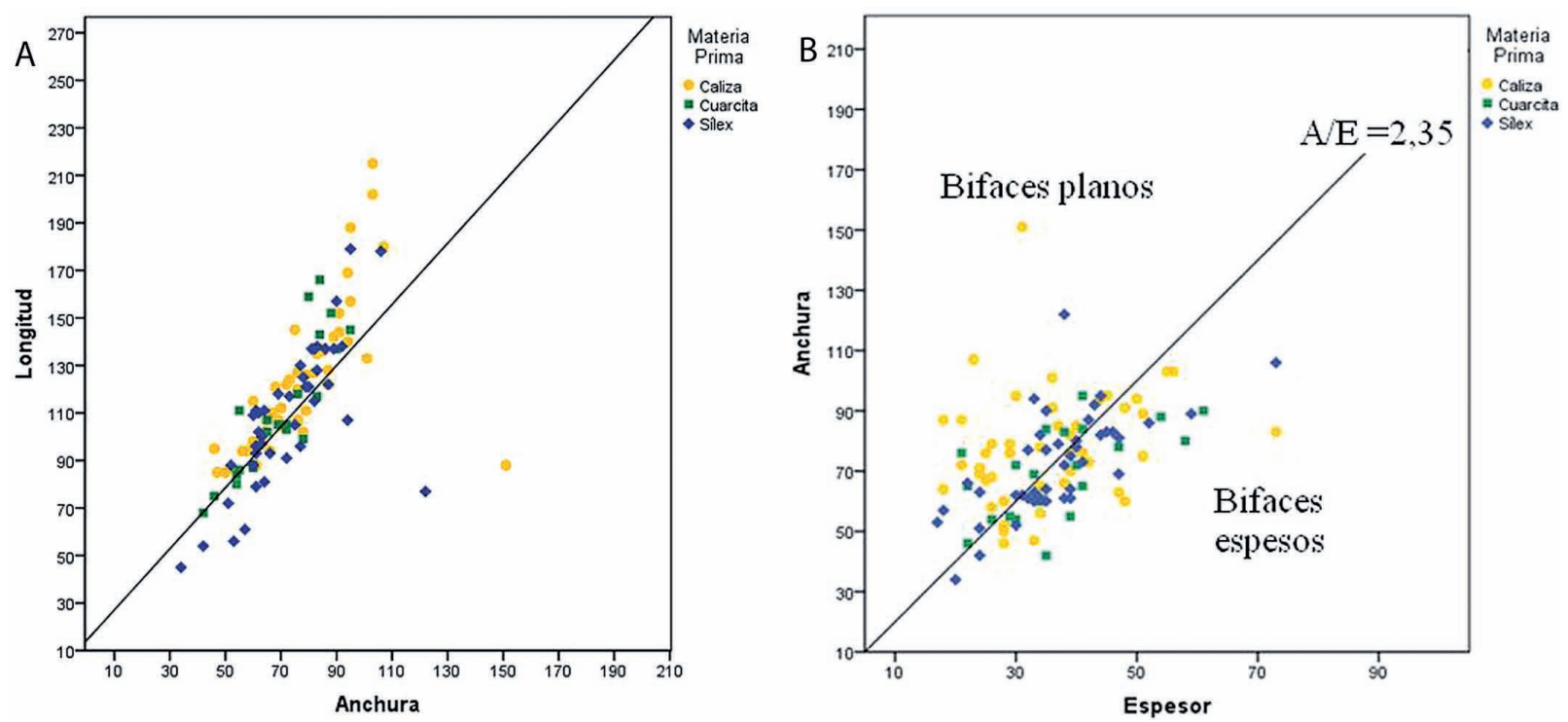

Fig. 6. Bifaces de Torralba. Colección marqués de Cerralbo: A. relación entre longitud y anchura; B. relación entre anchura y espesor.

como bilateral es muy somera: la talla, limitada, no supera las 5-6 extracciones por superficie. Una parte de estas piezas pueden conceptuarse como preformas, bifaces abandonados en pleno proceso de producción. Sin embargo 5 piezas de sílex, recibieron retoque específico para crear en sus filos frentes de raedera.

Una decena de ejemplares es definible como bifaces-soporte de útil (Boëda 2001) por tener sectores de filo transformados mediante retoque. La mayoría son de sílex y el retoque, a veces hecho con percutor orgánico, establece unidades tecno-funcionales específicas, casi exclusivamente raederas (Fig. 7: 5). Aparte de estos bifaces-útiles otros 41 verdaderos bifaces presentan retoque final de configuración cuyo objetivo es definir de modo preciso su simetría bilateral.

Junto a las preformas mencionadas, la presencia de fragmentos característicos como puntas (Fig. 4: 1) y al menos 5 lascas de sílex procedentes de la elaboración de bifaces (Fig. 4: 2-5) permite reconocer actividades de uso, conformación y mantenimiento de estas piezas en el propio yacimiento.

En la serie del marqués de Cerralbo hay también verdaderos hendedores (20) y piezas de aspecto formal y dimensiones semejantes confeccionadas sobre cantos aplanados (Fig. 9: 5). El uso de sílex, dominante (60\%) en el grupo, es una peculiaridad interesante del yacimiento ya que lo habitual en el Achelense del interior peninsular (Querol y Santonja 1979) es el empleo de cuarcita. En Torralba esta roca y la caliza compacta jurásica se emplean en cuatro casos $(20 \%)$ cada una por la similaridad en su respuesta a la confección de hendedores.

Por lo general la configuración de los hendedores de la serie es intensa, materializada en tallas bifaciales profundas, mediante percutor duro. Pueden casi eliminar los caracteres de la lasca soporte, aproximando parte de estos artefactos al tipo V de Tixier (1956). Salvo dos ejemplares sobre lasca cortical de cuarcita, encuadrables en los tipos 0 y I de Tixier, el resto de los hendedores con soporte determinable de la colección del marqués de Cerralbo (18) corresponden al tipo II, sobre lasca ordinaria. El ejemplar de tipo 0 (Fig. 9: 2) es de gran tamaño (192 x 141 x $48 \mathrm{~mm})$ y el de tipo I esta reavivado en su cara inferior, igual que ocurre en otros ejemplares del tipo II (Figs. 4: 7-9 y 9: 3). Seis hendedores de tipo II se elaboraron sobre lascas rectangulares muy regulares, obtenidas en núcleos discoidales de tamaños sensiblemente superiores a los registrados en el yacimiento (p. e. Fig. 4: 7 y 9). En otros ocho la reducción bilateral llega casi a borrar el anverso 
de la lasca soporte (Figs. 5: 2 y 9: 3), lo que podría permitir considerarlos tipos intermedios entre II-V (Querol y Santonja 1979). También en los hendedores se observa un retoque transformativo en sectores periféricos que da lugar a utensilios específicos, en particular raederas (Fig. 4: 7).

\subsection{Estudio de la colección Howell}

\subsubsection{Fase de captación}

Al contrario de lo que sucede en la colección del marqués de Cerralbo, y sin duda efecto de la metodología de excavación aplicada, la fase de captación de materias primas sí se reconoce en la serie formada en las excavaciones de los años sesenta. Además de material tallado se conservaron 6 cantos rodados, uno de caliza y cinco de cuarcita, con huellas de impacto derivadas de su empleo como percutores. Junto a ellos también se recogieron un total de 29 cantos, fundamentalmente de cuarcita (20), pero también de caliza (7) y de cuarzo (2), sin evidencias de acción antrópica, pero que sugieren su posible introducción intencionada en el yacimiento. El tamaño de los cantos calcáreos (Tab. 3) es el principal apoyo para esta suposición: Por su parte los cantos de cuarcita y cuarzo no son locales y forzosamente debieron ser introducidos.

\subsubsection{Fase de producción}

A esta fase corresponden 761 piezas (Tab. 1), el $78 \%$ de la serie ( $87 \%$ sin productos menores). Incluye 682 lascas y fragmentos, 63 núcleos y 16 chunks. La colección Howell cuenta además con 104 pequeños debris y lascas de talla inferiores a $10 \mathrm{~mm}$. Estos restos menores carecen de atribución estratigráfica, lo cual sugiere que probablemente fueron obtenidos al cribar el sedimento excavado. Estas tareas no eran habituales a principios de siglo, lo que explica su ausencia en la serie del marqués de Cerralbo.

Las lascas ordinarias son el elemento dominante. Los productos con dorso y, en especial, los corticales son claramente deficitarios, man- teniéndose la estructura observada en la colección del marqués de Cerralbo. Mayoritariamente encontramos lascas no corticales $(70,7 \%)$ o con escasos restos corticales $(23,5 \%)$ de clara tendencia cuadrangular y dimensiones medias de $35 \times 35$ x $16 \mathrm{~mm}$, excluyendo las grandes lascas-soporte empleadas en la configuración de bifaces y hendedores (Tab. 4).

Las materias primas mayoritarias del lascado son el sílex $(57,3 \%)$ y la cuarcita $(37,6 \%)$. La caliza es menos frecuente que en la serie del marqués de Cerralbo (3.8\%). El cuarzo (1,3\%) tiene nuevamente una representación muy marginal.

Tan solo se han identificado 14 lascas corticales, y entre los productos de acondicionamiento 18 lascas con dorso desbordante. Hay hay 2 lascas con dorso natural y 2 puntas pseudolevallois, una retocada (Fig. 5: 7) procedentes de núcleos discoides. De nuevo se constata la falta de productos levallois. La morfología de los talones refleja, como en la serie anterior, una preparación elemental de las superficies de percusión, con hegemonía de formas lisas $(63,6 \%)$ y algunos talones corticales $(8,1 \%)$ y diedros $(5,6 \%)$. Se reconocen talones facetados en 28 piezas $(4,1 \%)$ y ocasionalmente lineales $(1,9 \%)$ y puntiformes $(0,3 \%)$. En las restantes lascas $(16,4 \%)$ el talón ha sido suprimido o se ve afectado por retoque impidiendo apreciar la morfología original. Cinco lascas de sílex fueron obtenidas a partir de caras ventrales de lascas mayores. Solo dos de ellas responderían quizás al método kombewa, al tratarse de extracciones únicas susceptibles de predeterminación por el abombamiento de la cara bulbar de la lasca soporte, pero pudieron originarse en el avivado de hendedores o en la conformación bifacial de unidades sobre lasca.

El total de 63 núcleos es similar al reconocido en la colección del marqués de Cerralbo, pero su porcentaje sobre el total de la colección es inferior (7,2\%, productos menores excluidos). Son en su mayoría de cuarcita $(41,3 \%)$ o sílex $(36,5 \%)$. Los de caliza son más escasos $(19,0 \%)$ y más aún los de cuarzo $(3,2 \%)$, pero es una incidencia llamativa ya que esta materia prima es aún menos habitual entre los productos de talla del yacimiento.

Como soporte se recurrió con preferencia a cantos más o menos angulosos (26). En 11 casos se trata de lascas: 5 de cuarcita, 4 de sílex y 2 de caliza. Ninguno de estos núcleos puede considerarse Kombewa, ya que la explotación sobre la 
superficie ventral asocia varias extracciones, aunque en general escasas. En las 26 piezas restantes el soporte no puede ser identificado.

Los sistemas casuales o elementales son más frecuentes en caliza. En cuarcita hay casi equilibrio entre explotación elemental y sistemas más organizados como el bifacial (Fig. 4: 6), multipolar y discoide, que son dominantes en sílex. La intensidad de la explotación fue más acentuada en las rocas de mayor calidad. En 9 casos, la mayoría en sílex, el avanzado grado de explotación impide reconocer el esquema operativo aplicado. El esquema de explotación discoide, identificado en 16 piezas, es el más representativo de la colección. Son núcleos sometidos a una explotación a veces no invasora pero siempre de clara tendencia centrípeta. En un caso se conserva parte de una extracción central en un plano paralelo al plano principal de simetría que sugiere que podría tratarse de un núcleo levallois ultra explotado. Sin embargo en el estado final corresponde a un sistema de explotación discoidal bifacial, sin jerarquización de superficies (Fig. 9: 8). Los tamaños medios de los núcleos de esta serie $(58$ x 49 x $28 \mathrm{~mm}$ ) se observan en todas las materias primas, incluso uno en caliza y otro en cuarzo (Tab. 7).

\subsubsection{Fase de consumo}

En la colección Howell 336 piezas se modificaron mediante retoque o talla de conformación. Son 256 lascas retocadas, 4 núcleos con retoque

\begin{tabular}{|c|c|c|c|c|c|}
\hline \multirow{2}{*}{$\begin{array}{l}\text { Esquemas } \\
\text { operativos }\end{array}$} & \multicolumn{4}{|c|}{ Materia prima } & \multirow{2}{*}{ Total } \\
\hline & Caliza & Cuarcita & Cuarzo & Sílex & \\
\hline Agotados & - & 3 & 1 & 5 & 9 \\
\hline Casuales & 2 & 2 & - & - & 4 \\
\hline $\begin{array}{c}\text { Elementales } \\
\text { (mono y } \\
\text { bipolares) }\end{array}$ & 7 & 11 & - & 5 & 23 \\
\hline Bifaciales & - & - & - & 2 & 2 \\
\hline Multipolares & 2 & 5 & - & 2 & 9 \\
\hline Discoides & 1 & 5 & 1 & 9 & 16 \\
\hline Total & 12 & 26 & 2 & 23 & 63 \\
\hline
\end{tabular}

Tab. 7. Torralba. Esquemas de explotación de los núcleos en función de la materia prima.
(Tab. 6), 76 conformados, la mayoría macroutillaje achelense ( 60 bifaces, 12 hendedores y afines, 2 picos triédricos) y 2 cantos tallados. Utensilios retocados y configurados suponen el 38,5\% del total de la serie excluidos productos menores. El porcentaje parece algo elevado, por ejemplo en el nivel inferior, AS1, de Ambrona es el 27,2\% (Santonja y Pérez González 2001). Sin embargo es casi la mitad del que hemos registrado en la colección del marqués de Cerralbo.

Dominan los utensilios retocados sobre lasca, a los que se pueden añadir 3 raederas y 1 escotadura sobre núcleos agotados (Tab. 6). La selección de materias primas es muy clara: el $76 \%$ están configuradas en sílex y el $22 \%$ en cuarcita. Hay 4 piezas retocadas en caliza y 1 en cuarzo. Las dimensiones medias de los utensilios sobre lasca son significativamente superiores a las de los productos sin retocar (Tab. 8). La ligera tendencia hacia formas alargadas también puede considerarse un patrón de selección. Incluyen elementos de cierto tamaño, como algunas raederas convergentes (Fig. 5: 8), también observadas en la colección del marqués de Cerralbo.

El tipo de retoque identificado es mayoritariamente simple, directo y no muy penetrativo, regularizando el trazado de los filos pero sin producir excesivas modificaciones en el contorno de la lasca soporte. En las raederas abruptas, se reconoce un retoque de mayor intensidad. También con carácter minoritario se han observado retoques de tipo bifacial, y en una raedera desviada un frente escaleriforme formado por dos generaciones sucesivas de retoque.

En el catálogo tipológico las 128 raederas suponen casi la mitad de los retocados (Tab. 6). Se utilizaron de manera no intensiva, habitualmente con generaciones únicas de retoque, pero tan variadas como las de la colección del marqués de Cerralbo (Fig. 5: 2 y 7-9). Los 21 denticula-

\begin{tabular}{|c|c|c|c|c|c|c|}
\hline \multirow{2}{*}{} & \multicolumn{3}{|c|}{ Útiles sobre lasca } & \multicolumn{3}{c|}{ Lascas sin retocar } \\
\cline { 2 - 7 } & Mín. & Máx. & Media & Mín. & Máx. & Media \\
\hline L & 12 & 119 & $\mathbf{4 2 , 7 8}$ & 8 & 102 & $\mathbf{3 0 , 6 0}$ \\
\hline A & 9 & 102 & $\mathbf{4 1 , 5 3}$ & 9 & 111 & $\mathbf{3 1 , 0 2}$ \\
\hline E & 3 & 48 & $\mathbf{1 4 , 6 2}$ & 1 & 42 & $\mathbf{1 1 , 0 0}$ \\
\hline
\end{tabular}

Tab. 8. Torralba Comparativa de las dimensiones entre lascas retocadas y sin retocar en la colección Howell. 

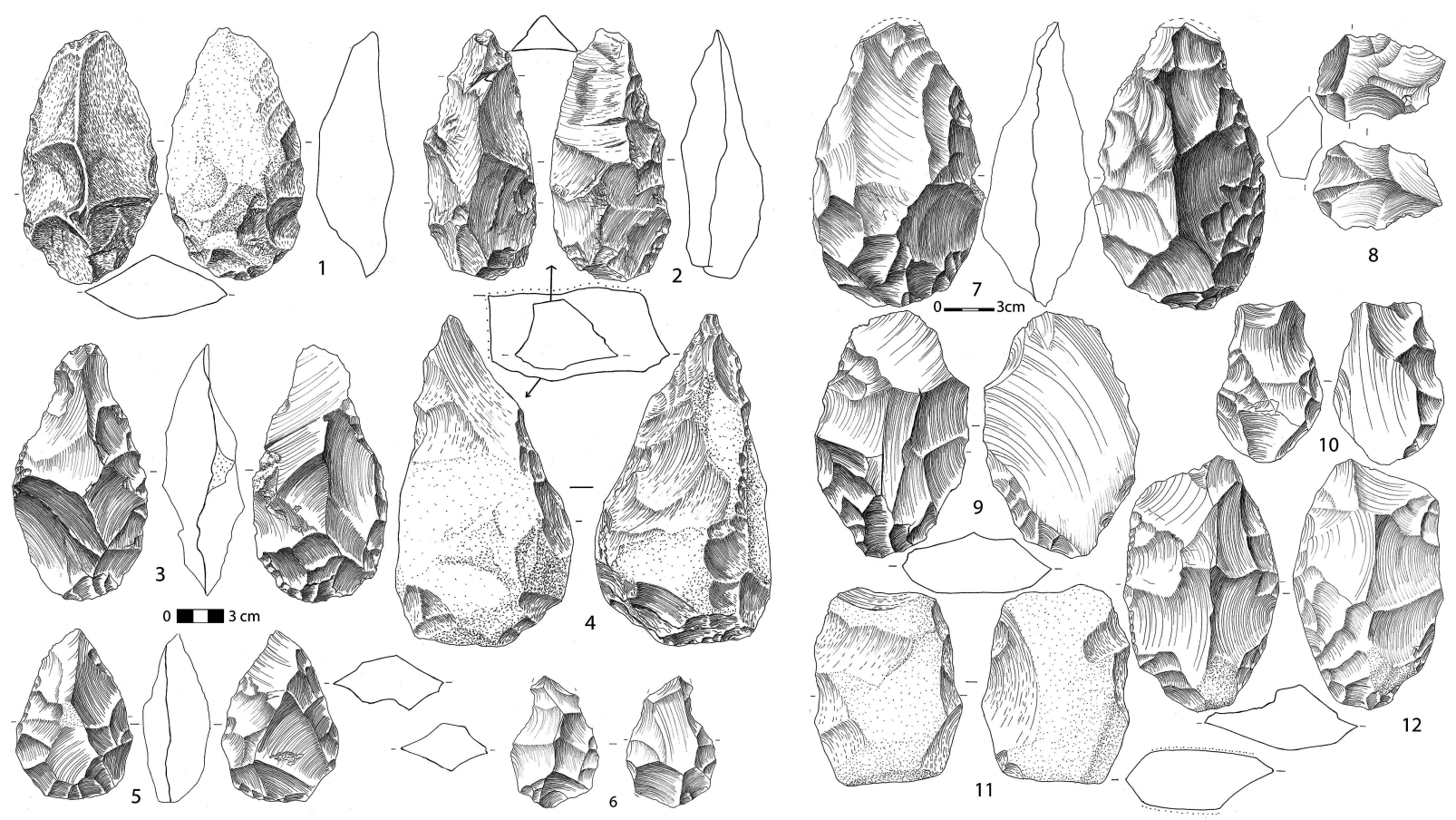

Fig. 7. Tipología de los bifaces de Torralba (1-10): 1-2 ovalar y ovalar estrecho espesos; 3 amigdaloide alargado; 4 ficron lanceolado; 5-6 amigdaloides (5 con retoque que conforma una raedera recta en el lateral izquierdo de la superficie principal; 6 con fractura antigua en la punta); 7 amigdaloide alargado; 9 ovalar parcial; 10 de filo transversal con morfología de hendedor; 12 de filo transversal y contorno ovalar acabado en parte con percutor blando; 8 núcleo discoidal bifacial; 11 placa con filo transversal y morfología de hendedor. Colecciones marqués de Cerralbo (4-5, 7) y Howell (1-2, 3, 6, 8-12). Materias primas: 1 cuarcita; 2, 4 caliza jurásica; 11 caliza; 3, 5-10, 12 sílex.

dos (Fig. 5: 5), incluyen una punta de Tayac. Los elementos progresivos son prácticamente inexistentes, cabe mencionar 3 raspadores, si bien atípicos (Fig. 5: 4), 3 perforadores y 7 utensilios compuestos. Estos combinan frentes de raedera, de denticulado, escotaduras y becs.

El utillaje conformado de carácter achelense no alcanza la dimensión que tiene en la serie del marqués de Cerralbo pero también aquí destaca. Forman el grupo 74 piezas: 60 bifaces, 9 hendedores más 3 piezas afines y 2 triedros. Los bifaces son más de las tres cuartas partes de las piezas conformadas y la relación hendedores/bifaces es de 1:6.7, casi idéntica a la de la colección del marqués de Cerralbo. Se observa también en esta serie un patrón similar en el uso de las materias primas: calizas compactas preferidas a sílex y menor utilización de cuarcita.

La mayoría de los 35 bifaces en caliza presenta configuraciones bifaciales y bilaterales parciales, equilibrándose mediante una mínima intensidad de talla. Las piezas en sílex (16) y en cuarcita (9) fueron sometidas a procesos de reducción más intensos, produciendo ejemplares volumétrica y bilateralmente equilibrados, en especial si se utilizaban lascas como soporte. Las dimensiones medias de los bifaces están en torno a 125 × 82 × $39 \mathrm{~mm}$ (Tab. 4), aunque la variabilidad de tamaños es notable, observándose valores máximos de $218 \mathrm{~mm}$ de longitud y $151 \mathrm{~mm}$ de anchura (Fig. 8). El percutor duro, poco pesado (Fig. 7: 12) se aplicó casi exclusivamente en la talla o, con cierta frecuencia, para el retoque de los filos. El retoque de regularización del contorno se usó, al menos, en 38 piezas y en 5 ejemplares definió unidades funcionales específicas, raederas en general, dando lugar a verdaderos bifaces-soporte de útil (Boëda 2001).

En las formas bien definidas predominan las siluetas espesas, fundamentalmente amigdaloides (Fig. 7: 3 y 6), lanceoladas y ovalares (Fig. 7: 1 y 
2). Es llamativa la presencia de 5 bifaces de filo transversal (Fig. 7: 12), con equivalencias formales claras con los hendedores (Fig. 9: 6). Las proporciones entre anchura y espesor (Fig. 8) marcan la existencia de bifaces definibles como planos (Bordes 1961). Insistimos en que la relación viene impuesta por las medidas del soporte -lascas o cantos calcáreos aplanados- y no resultan de una reducción bifacial intensa. Junto a estas formas regulares, fundamentalmente sobre soportes de materias primas de gran calidad, hay bifaces parciales (Fig. 7: 9) y preformas, piezas abandonadas en el proceso de elaboración, mayoritariamente en caliza pero también en sílex (Fig. 7: 11).

Los 9 hendedores registrados responden a parámetros técnicos similares a los de la serie del marqués de Cerralbo, aunque en la de Howell los ejemplares de cuarcita (6) dominan frente a los de sílex (3). Son piezas en general con talla de intensidad media que, si bien supone una modificación bilateral significativa, incluso alta en algunos casos (Figs. 9: 2 y 6), siempre permite reconocer el tipo de lasca soporte. Siguiendo el criterio clasificatorio antes aplicado (Tixier 1956) se ha identificado 1 ejemplar de tipo 0 sobre lasca cortical (Fig. 9: 3), 7 hendedores de tipo II, sobre lascas ordinaria y uno de tipo VI sobre lasca Jano (Fig. 9: 4). Como en la serie del marqués de Cerralbo, alguno de los hendedores del tipo II se realizaron sobre lascas de contorno rectangular bastante simétricas, procedentes de núcleos discoidales. En conjunto esta categoría de macroutillaje presenta unas dimensiones medias de 133 x 85 x $45 \mathrm{~mm}$, alcanzando en un caso $19 \mathrm{~cm}$ de longitud (Fig. 9: 1). Estos tamaños no encuentran correspondencia en los de las lascas de la serie.

Sumamos finalmente a los hendedores 3 piezas configuradas sobre canto de sílex, cuarcita y caliza (Fig. 7: 11). No responden al concepto de hendedor en sí pero se definen por un equilibrio formal similar y por la búsqueda de un filo transversal sin retoque.

El macroutillaje conformado incluye 2 picos triédricos y 2 cantos trabajados. Los picos triedrícos tienen una punta de sección triangular definida por talla bifacial opuesta a una base espesa. Son característicos sobre cantos rodados de sílex (145 x 82 x $38 \mathrm{~mm})$ y caliza $(150$ x 64 x $45 \mathrm{~mm})$. Los cantos trabajados son de cuarcita $(82 \times 82 \times 55$ $\mathrm{mm})$ y caliza $(130 \times 110 \times 35 \mathrm{~mm})$, el primero con filo convergente distal y el segundo sobre una placa con extracciones bifaciales periféricas.

\section{DISCUSIÓN}

Las series industriales de Torralba estudiadas alcanzan un total de 1529 piezas: 552 de
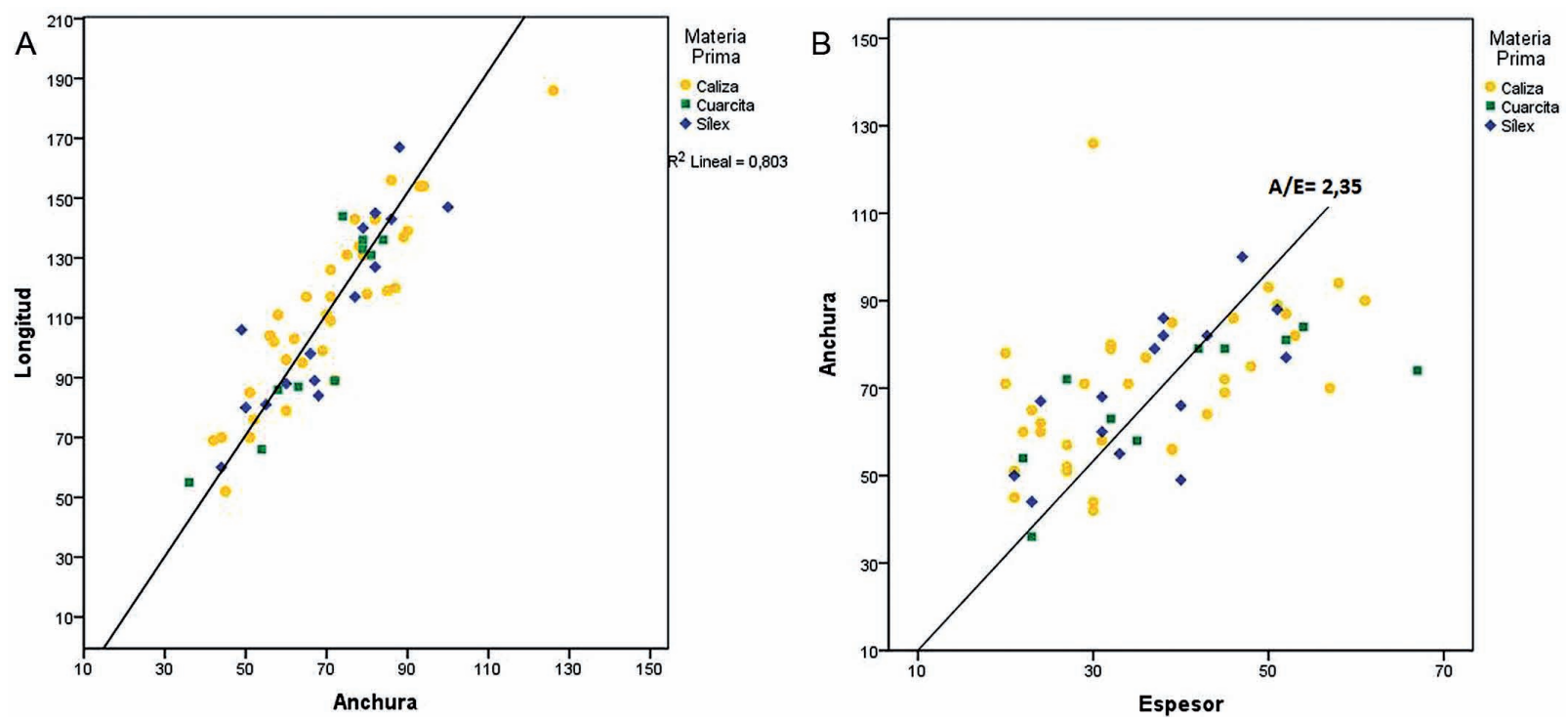

Fig. 8. Bifaces de Torralba. Colección Howell: A. relación entre longitud y anchura; B. relación entre anchura y espesor. 
la colección del marqués de Cerralbo y 977 de la colección Howell (en adelante SC y SH respectivamente). La falta de información respecto a su posición estratigráfica solo permite valoraciones globales. Cada serie aporta matices que afectan a su composición estructural y han sido tomadas en consideración. La estructura de ambas colecciones desde la perspectiva de la cadena operativa acusa claras discontinuidades, más acentuadas en $\mathrm{SC}$, que parecen derivar de recogidas incompletas y de una conservación selectiva.

Las dos series presentan la misma variedad de materias primas (Tab. 2), calizas obtenidas cerca del yacimiento, si bien no estrictamente locales, y cuarcitas, algo de cuarzo y sílex introducidas desde distancias mayores (Freeman 1991: 77-83; Parcerisas 2006). En ambas en torno a la mitad de las piezas se elaboraron en sílex. En la otra mitad las proporciones de cuarcita y caliza son inversas: en la SC dominan las calizas y en la SH las cuarcitas son más frecuentes. Podría tratarse de una diferencia real, propia de las zonas excavadas en uno y otro momento. En unas excavaciones de principios del siglo XX resultaría más lógico que se hubiera manifestado la tendencia inversa, conservándose con mayor facilidad utillaje en cuarcita que en caliza.

La introducción de materia prima en bruto queda atestiguada en $\mathrm{SH}$ por los cantos rodados de cuarcita con estigmas de percusión. Su ausencia en SC puede perfectamente obedecer a que este tipo de materiales no fuera conservado en la intervención del marqués de Cerralbo. La existencia de núcleos en las dos series sugiere el desarrollo de procesos de debitage en el propio yacimiento. Sin embargo introduce algunos interrogantes el que los índices de corticalidad, que pueden revelar la ejecución in situ de las primeras fases de reducción de soportes naturales, sean bajos. Las lascas totalmente corticales son insignificantes en ambas series. En SC solamente hay 5 sobre un total de 311 lascas de todas las categorías. En SH son 14, casi todas de cuarcita, sobre un total de 682. Sin embargo si atendemos a las lascas con restos de córtex las proporciones resultan más normales: $88(28 \%)$ en SC y $160(24 \%)$ en SH. El déficit de productos totalmente corticales apuntaría más bien, entonces, a conservaciones selectivas del registro tanto en una época como en la otra. La alternativa sería la ejecución de los procesos más iniciales de reducción fuera del yacimiento, o en áreas distintas a las excavadas.

La fase de producción es mayoritaria en las dos colecciones: el $68 \%$ en SC y el $87 \%$, aún sin considerar productos menores, en $\mathrm{SH}$. Atendiendo a las lascas, el elemento mayoritario, las rocas del grupo sílex $(64,7 \%$ y $57,3 \%)$ y las cuarcitas $(22,9 \%$ y $37,6 \%)$ se emplearon de manera comparable en SC y SH. La caliza, como reflejaban las proporciones globales, sigue estando bastante menos representada en $\mathrm{SH}(3,8 \%)$ que en SC $(11,6 \%)$. Ello refuerza la impresión de que pueda tratarse de un rasgo propio de la industria procedente de dos zonas distintas del yacimiento.

El mayor recurso a la caliza en SC podría influir en que los tamaños medios distinguidos en los productos de esta colección sean sensiblemente mayores (Tab. 4). Pero conviene tener en cuenta que la ausencia total de esquirlas en SC sugiere que las piezas de menor tamaño no se recogieron o no fueron conservadas en las excavaciones de principios del siglo XX, lo cual se estaría acusando en las diferencias de tamaño observadas en el lascado de las dos series.

Los patrones de explotación de los núcleos son totalmente similares en ambas colecciones. Se reconocen acciones poco organizadas, extracciones aisladas oportunistas o adaptadas a los volúmenes naturales especialmente en las piezas en caliza y métodos más organizados, multipolares y discoides bien desarrollados, en nódulos de sílex, cantos de cuarcita y ocasionalmente sobre lascas de una y otra materia prima.

La proporción de núcleos y chunks en la fase de producción es considerablemente mayor en SC que en $\mathrm{SH}$ (17\% frente a 10\%). También lo es, como valoraremos a continuación, la de macroutillaje. En consecuencia la relación entre bases explotadas (núcleos más configurados) y lascas resulta más desequilibrada en SC: 3 lascas por cada dos soportes tallados. Esto refuerza la impresión de que, en aquellas primeras excavaciones, se aplicó una conservación selectiva de las piezas mayores y más elaboradas en detrimento de las menores y más elementales, no solo esquirlas sino también lascas pequeñas y corticales.

En los núcleos de ambas series la utilización de materias primas acusa proporciones y tendencias que solo coinciden parcialmente con las observadas en las lascas (Tab. 9). El sílex deja de ser el recurso mayoritario en $\mathrm{SH}$, reemplazado por

Trab. Prehist., 72, N. ${ }^{\circ}$ 1, enero-junio 2015, pp. 41-63, ISSN: 0082-5638

doi: $10.3989 /$ tp. 2015.12143 

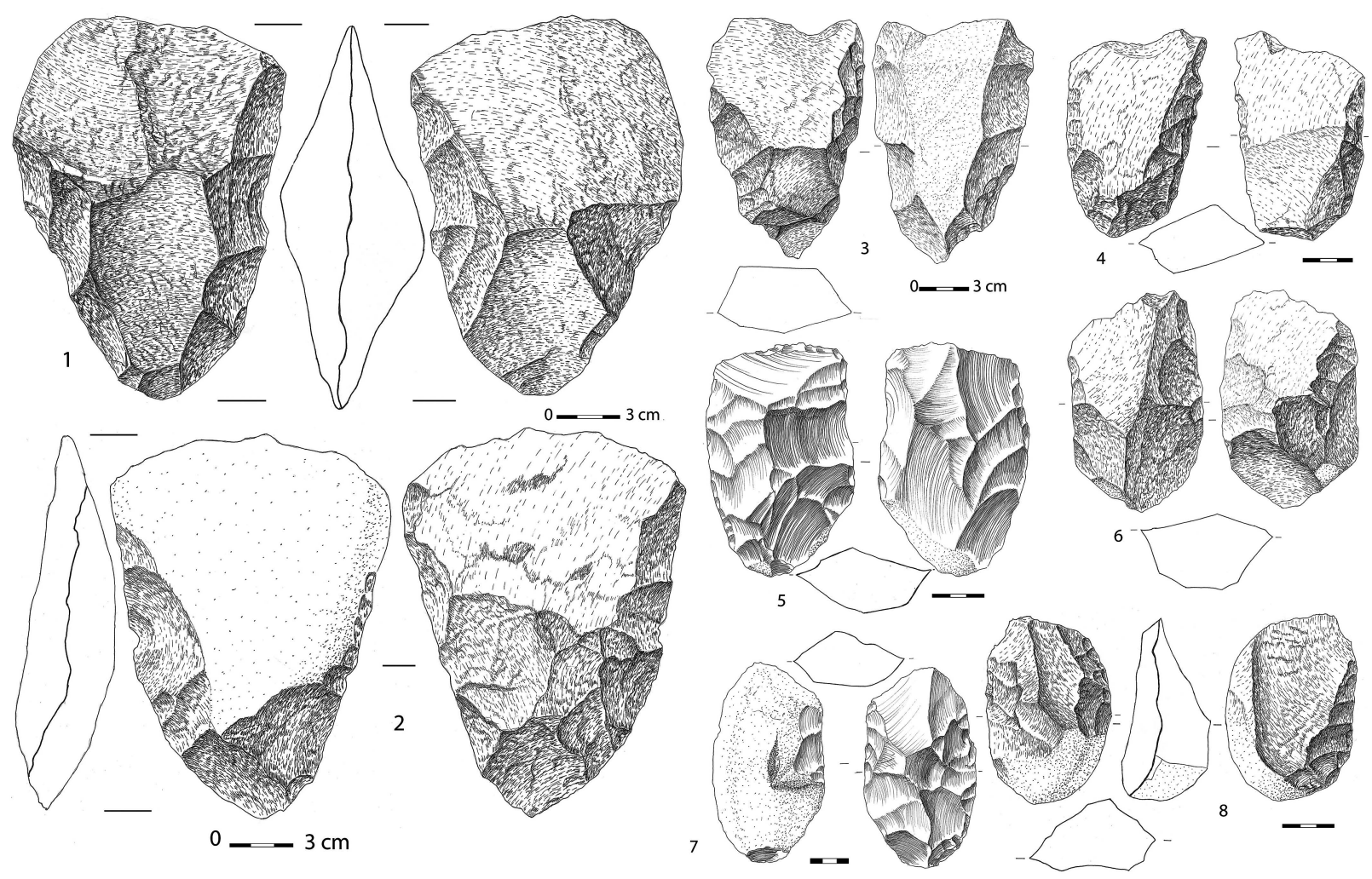

Fig. 9. Torralba. Hendedores (1-6): 1, 5 (retallado) tipo II; 2-3 tipo 0; 4 tipo VI; 6 con talla bifacial intensa pero insuficiente para considerarlo tipo V; 7 preforma de bifaz; 8 canto tallado con filo transversal afín a hendedor.

Colecciones marqués de Cerralbo $(2,5,8)$ y Howell $(1,3-4,6-7)$. Materias primas: cuarcita $(1-4,6,8)$, sílex $(5,7)$.

la cuarcita, mientras crece en las dos el recurso a las calizas. Los porcentajes de sílex y cuarcitas guardan en SH y SC una proporcionalidad similar en lascas y núcleos, pero las calizas, cuyo porcentaje entre las lascas triplicaba en $\mathrm{SC}$ al de $\mathrm{SH}$, en los núcleos es solo 1.7 veces mayor. Este aparente desfase podría revelar ausencias en la conservación de núcleos calcáreos en $\mathrm{SC}$ o de lascas de esta roca en SH. Alternativamente podría quedar explicada por una superior producción de lascas

\begin{tabular}{|c|c|c|c|}
\hline Colección & Sílex & $\begin{array}{c}\text { Cuarcita } \\
\text { y cuarzo }\end{array}$ & Caliza \\
\hline $\begin{array}{c}\text { M. Cerralbo } \\
(\mathrm{N}=61)\end{array}$ & $47,5 \%$ & $17,7 \%$ & $33,9 \%$ \\
\hline $\begin{array}{c}\text { Howell } \\
(\mathrm{N}=61)\end{array}$ & $36,1 \%$ & $44,3 \%$ & $19,7 \%$ \\
\hline
\end{tabular}

Tab. 9. Torralba. Materias primas de los núcleos. de los núcleos calcáreos de $\mathrm{SC}$, que traduciría un uso diferenciado de las materias primas en uno y otro espacio. Sin embargo las dos series comparten una intensidad comparable en las secuencias de explotación de los núcleos, acentuada sobre las rocas de mayor calidad. Las diferencias en el rendimiento de las calizas no pueden por tanto haber sido significativas.

Los desajustes entre las dos colecciones resultan más acentuados en el peso relativo que en cada una presentan los elementos retocados y conformados, nada menos que el $64,5 \%$ en SC y poco más de la mitad, el $38,5 \%$ en $\mathrm{SH}$. Son porcentajes elevados. Para el segundo es posible encontrar referencias aproximadas en conjuntos excavados bien controlados, mientras para el de $\mathrm{SC}$ solo se podrían hallar paralelos en colecciones achelenses de yacimientos al aire libre. La proporción de lascas retocadas respecto a la producción total, elevadísima también en SC $(66,2 \%)$ y 
puede que algo elevada en SH (37,5\%), refuerza también la impresión de que SC acusa fuertes sesgos selectivos, que resultarían menos patentes en la formación de $\mathrm{SH}$.

En las dos colecciones se prefiere retocar lascas de sílex, sin que haya una especial elección de soportes en cuarcita con esta finalidad. En cambio, los tamaños no se comportan igual. En SC coinciden los de lascas retocadas y no retocadas mientras en SH son claramente mayores los utensilios. Recordando el déficit en los productos de menor tamaño observado en SC, se concluye que el resultado obtenido en $\mathrm{SH}$ parece más pertinente como rasgo definitorio de la industria de Torralba.

La naturaleza y los resultados del retoque resultan más comparables. En SC y $\mathrm{SH}$ prevalece el retoque directo, simple y poco penetrativo. Las piezas afectadas por retoque intenso que permitan suponer avivados sucesivos son minoritarias. En las dos series las raederas, variadas por igual (Tab. 6), son el componente mayoritario, de forma algo más acentuada en SC que en $\mathrm{SH}(59,4 \%$ y 49,2\%). Los utensilios de carácter progresivo, como perforadores típicos o raspadores, son poco numerosos pero existen en ambas colecciones. Lo mismo sucede con los núcleos retocados, sin que en ninguna halla una tendencia acusada a la ramificación.

El elevado porcentaje de macroutillaje achelense en SC $(25,7 \%)$ debe aceptarse también como resultado de sesgos selectivos. Su proporción en $\mathrm{SH}(8,5 \%)$ debe estar menos alterada, si bien resulta interesante observar que la relación bifaces/hendedores guarda en ambas un valor similar: 6,1 en SC y 6,7 en SH. Los bifaces son con claridad el componente principal, pero los hendedores característicos son frecuentes en ambas series. La presencia de picos triédricos -2 en $\mathrm{SH}-\mathrm{y}$ de cantos trabajados resulta por el contrario irrelevante.

En SH la caliza es la materia prima claramente preferida en la elaboración de bifaces, y en SC también domina ligeramente sobre el sílex. La cuarcita, minoritaria tanto en $\mathrm{SH}$ como en SC en los bifaces domina sin embargo en los hendedores de SH. Ese papel, anómalo -si lo evaluamos en el contexto general del achelense ibérico (Santonja y Pérez-González 2010)- corresponde al sílex en SC. Con independencia de que los sesgos reconocidos en la formación de SC impidan elevar a categoría esta observación, el hecho cierto es que en Torralba se recurrió con meridiana continuidad al sílex para fabricar hendedores.

Las medidas y el equilibrio dimensional del macroutillaje difieren poco en ambas series: tamaños medios en torno a $12 \mathrm{~cm}$ de longitud y máximos de hasta $22 \mathrm{~cm}$, algo mayores en SC (Tab. 4). Entre los bifaces se observan ejemplares aparentemente planos (Bordes 1961), con una relación anchura/espesor superior a 2.35 (Figs. 7 y 8). La proporción está determinada por la elección del soporte (lascas y cantos calcáreos aplanados) y en escasa medida por la intensidad de la reducción bifacial que, en general, fue más intensa en las piezas de sílex y cuarcita. En la configuración de bifaces y hendedores se empleó fundamentalmente percutor mineral, pero no es infrecuente observar la aplicación de percutores orgánicos o poco pesados en los acabados finales (p. e., Fig. 7: 12).

Las formas apuntadas -lanceoladas y amigdaloides- son más frecuentes que las ovalares y que los bifaces con filo transversal. Predominan en cualquier caso los bifaces parciales, sobre todo en caliza, con siluetas poco regulares. En las dos series cierto número de bifaces con retoque transformativo en sectores limitados del filo encajan en el concepto de bifaz-soporte de útil definido por Boëda (2001). En los hendedores el soporte preferido son lascas ordinarias rectangulares, con el eje técnico perpendicular a la dimensión mayor, en uno de cuyos extremos se sitúa el filo del utensilio. Con frecuencia estas lascas proceden de núcleos discoidales de tamaños mayores que los registrados en cualquiera de las dos colecciones estudiadas. Esta elección constituye otra peculiaridad de Torralba frente al recurso más común a lascas corticales en las series achelenses de la Meseta (Querol y Santonja 1979).

\section{CONCLUSIONES}

Torralba es un yacimiento del final del Pleistoceno medio, probablemente del MIS 7 a tenor de las dataciones numéricas obtenidas en el propio yacimiento y en formaciones fluviales del Alto Henares correlacionadas. La industria achelense de Torralba sería por tanto más reciente que la de las dos unidades reconocidas en Ambrona; posterior tanto a los niveles inferiores con materiales

Trab. Prehist., 72, N. ${ }^{\circ}$ 1, enero-junio 2015, pp. 41-63, ISSN: 0082-5638

doi: $10.3989 /$ tp.2015.12143 
atribuidos también al tecnocomplejo Achelense como a los intermedios, con series Achelense superior encuadradas en el Paleolítico medio (Santonja y Pérez-González 2001，2006; Santonja et al. 2014).

Los niveles de los que procede la industria de Torralba estudiada en estas páginas son de origen fluvial. El material arqueopaleontológico que contenían pudo experimentar movimientos proporcionales a su forma y tamaño, efecto acusado en el rodamiento que muestran las aristas de las piezas líticas, en ocasiones intenso. La información que aporta el estudio tecnológico que aquí presentamos y todas las estimaciones referidas a las características espaciales del yacimiento deben entenderse desde esta perspectiva.

De acuerdo con la planimetría propuesta por Howell en 1961 y con nuestras propias observaciones, las intervenciones realizadas por el marqués de Cerralbo y por el equipo norteamericano habrían prácticamente agotado dos terceras partes del yacimiento en los sectores oriental y central del mismo (Fig. 1). En esas zonas solo cabe esperar que subsistan limitadas superficies sin excavar, conservadas gracias a la irregularidad de las catas del marqués de Cerralbo. En la zona occidental, si la delimitación establecida por Howell en la campaña de 1961 se confirma, podrían llegar a $1500 \mathrm{~m}^{2}$ de yacimiento.

Se desconoce la superficie exacta intervenida en las campañas de 1909-1913 y es obvio que la cantidad de restos conservada es inferior al contenido real de los niveles excavados. Aun teniendo en cuenta los dos factores la densidad de industria registrada en Torralba en el conjunto de las excavaciones no resulta elevada. Si suponemos que el marqués de Cerralbo excavó entre 1000 y $1500 \mathrm{~m}^{2}$, según el total de piezas conservadas (568: 552 estudiadas), el conjunto de los niveles excavados habría aportado 1 pieza cada $1,8 \mathrm{o}$ cada 2,6 $\mathrm{m}^{2}$. En la primera campaña de Howell las cifras son parejas. De los $450 \mathrm{~m}^{2}$ excavados en 1961 proceden 182 piezas, 1 por cada $2,5 \mathrm{~m}^{2}$. En 1962-1963 el rendimiento resultaría algo superior: en los $576 \mathrm{~m}^{2}$ excavados por Howell con la cooperación de Freeman el número de piezas obtenido varía entre 689 y 790, es decir, 1 pieza cada $0,7 / 0,8 \mathrm{~m}^{2}$. Probablemente constituye la parte de las series antiguas de Torralba con menores sesgos selectivos. En todo caso, como ya señaló Freeman en 1991, las densidades globales por $\mathrm{m}^{3}$ no serían muy superiores a 1 pieza en ningún sector del yacimiento.

Densidades tan bajas sugieren presencias humanas esporádicas e intervenciones muy puntuales o de baja intensidad, pero el patrón de captación de materias primas se mantiene en líneas generales a través de la secuencia estratigráfica y parece implicar constantes en el uso del territorio. Se captan cuarcitas en la zona de Miño, rocas tipo sílex en un territorio considerable, quizás más de $50 \mathrm{~km}$ alrededor del yacimiento, y calizas compactas muy seleccionadas en un entorno más inmediato. Será en todo caso importante profundizar y llegar a un conocimiento más exacto de las pautas de aprovisionamiento registradas en Torralba. La comparación con las referencias equivalentes -mismo territorio de captación- que pueden aportar las distintas unidades del inmediato yacimiento Ambrona cubriría un rango temporal en torno a $200 \mathrm{ka}$ en el tercio final del Pleistoceno medio.

Ciñéndonos a las dos colecciones estudiadas las variaciones observadas en el uso de materias primas, condicionadas insistimos por los sesgos selectivos introducidos, no parecen revelar diferencias sustanciales, salvo quizás el sorprendente mayor recurso a rocas calizas detectado en el área oriental del yacimiento. La existencia de núcleos y lascas de variadas categorías demuestra en todo caso que en la localidad se talló a partir de soportes de cuarcita y sílex introducidos desde el exterior. La carencia de lascas corticales en las dos series sugiere que se pudo llevar al yacimiento materia prima sometida previamente a procesos iniciales de reducción. A su vez la ausencia de núcleos con tamaño suficiente para proporcionar las lascas-soporte de algunos bifaces y de los hendedores evidencia que este utillaje debió introducirse ya configurado.

Bifaces y hendedores permiten integrar la industria de Torralba en el tecnocomplejo Achelense. Sin embargo también se observan en Torralba elementos tecnológicos progresivos, en especial bifaces y hendedores soporte de útil, que plantean la necesidad de contrastar si en alguno de los niveles de Torralba existen tradiciones tecnológicas encuadrables en el Paleolítico medio, como es el caso de Ambrona (Santonja y Pérez-González 2010). En un contexto general del Achelense europeo resulta en cualquier caso importante subrayar la presencia en Torralba de verdaderos 
hendedores en sílex, ya que existe alguna tendencia a vincular de manera estrecha estos utensilios con la disponibilidad de cuarcita. Este yacimiento demostraría que la elaboración de tales artefactos no está tan condicionada por la materia prima.

Teniendo en cuenta las cronologías numéricas obtenidas, el tecnocomplejo achelense habría estado presente en la zona desde el MIS 11 (AS1, Ambrona) hasta el MIS 7, cronología de Torralba. En etapas intermedias, MIS 9 o 10, otras tradiciones industriales vinculadas al Paleolítico medio (AS6, Ambrona) tienen presencia en el área. Torralba constituiría uno de los yacimientos achelenses de fecha más reciente identificados en el sur de Europa, con edad comparable a otros conocidos en el Jarama-Manzanares, cuenca del Duero y Aquitania (Santonja et al. 2014).

\section{AGRADECIMIENTOS}

Los resultados que presentamos están basados en el trabajo de investigación realizado por BS$\mathrm{CV}$ en el Programa de doctorado del Departamento de Prehistoria de la Universidad Complutense en el año 2009. Su actualización y discusión se enmarca en el Proyecto CEN186A12-1 de la Junta de Castilla y León. Agradecemos los permisos concedidos por el Museo Numantino de Soria, el Museo Arqueológico Nacional y el Museo Nacional de Ciencias Naturales para estudiar las colecciones de industria lítica de Torralba (colecciones del marqués de Cerralbo y Howell) a su cargo, así como la información y facilidades prestadas por Carmen Cacho y Juan Antonio Martos (Departamento de Prehistoria, MAN), Patricia Pérez Dios (Departamento de Colecciones, MNCN) y Elías Terés y Marian Arlegui (MN de Soria). Muy en especial agradecemos la colaboración desinteresada de Raquel Rojas Mendoza en la realización de los dibujos de industria lítica.

\section{BIBLIOGRAFÍA}

Aguirre, E. 2005: "Torralba y Ambrona. Un siglo de encuentros". En M. Santonja y A. Pérez-González (eds.): Los yacimientos Paleoliticos de Ambrona y Torralba (Soria), Zona Arqueológica 5, Museo Arqueológico Regional. Madrid: 40-77.
Bascones, L. y Martínez Álvarez, F. 1981: Mapa Geológico de España, E 1: 50.000. Maranchón. IGME. Ministerio de Industria y Energía. Madrid.

Biberson, P. 1968: "Les gisements Acheuléens de Torralba et Ambrona (Espagne). Nouvelles précisions". L'Anthropologie 72 (3/4): 241278.

Boëda, E. 2001: "Determination des unités tecno-fonctionelles de pièces bifaciales provenant de la couche acheuléenne C'3 Base du site de Barbas I'. En D. Cliquet (ed.): Les industries à outils bifaciaux du Paléolithique moyen d'Europe occidentale. Études et Recherches Archéologiques de l'Université de Liège 98. Liège: 51-75.

Boëda, E.; Geneste, J.-M. y Meignen, L. 1990: “Identification de chaînes operatories lithiques du Paléolithique ancien et moyen". Paléo 2: 43-80.

Bordes, F. 1961: Typologie du Paléolithique ancien et moyen. Imprimeries Delmas. Bordeaux.

Bourguignon, L. 1998: "Le débitage Quina de la couche 5 de Sclayn: Eléments d'interpretation". En M. Patou-Mathis y D. Bonjean (eds.): Recherches aux grottes de Sclayn 2. Études et Recherches Archéologiques de l'Université de Liège 79. Liège: 249-276.

Bourguignon, L. y Faivre, J.-PH. y Turq, A. 2004: “Ramification des chaînes opératoires: une spécifité du Moustérien?". Paleo 16: 37-48.

Butzer, K. W. 1965: "Acheulian Occupation Sites at Torralba and Ambrona, Spain. Their Geology". Science 150: 1718-1722.

Carbonell, E.; Díez, C.; Enamorado, J. y Ortega, A. 1987: "Análisis morfotécnico de la industria lítica de Torralba (Soria)". Antropología/Etnografía 4: 201216.

Falguères, Ch.; Bahain, J.-J.; Pérez-Gonzalez, A.; Mercier, N.; Santonja, M. y Dolo, J.-M. 2006: "The Lower Acheulian site of Ambrona, Soria (Spain): ages derived from a combined ESR/U-series model". Journal of Archaeological Science 33: 149-157.

Freeman L. G. 1975: "Acheulian Sites and Stratigraphy in Iberia and the Maghreb". En K. W. Butzer y G. Isaac (eds.): After the Australopithecines. Mouton Pub. The Hague Paris: 661-744.

Freeman, L. G. 1991: "What mean these stones? Remarks on raw material use in the Spanish Paleolithic". En A. Montet-White y S. Holen (eds.): Raw Materials Economy among Prehistoric Hunter Gatherers. Univ. of Kansas Press. Lawrence: 73-125.

González Echegaray, J. y Freeman, L. G. 1998: Le Paléolithique inférieur et moyen en Espagne. Éditions Jerôme Millon. Grenoble.

Howell, F. C.; Butzer, K. W. y Aguirre, E. 1962: Noticia preliminar sobre el emplazamiento achelense de Torralba. Excavaciones Arqueológicas en España 10. Ministerio de Cultura. Madrid.

Howell, F. C.; Butzer, K. W.; Freeman, L. G. y Klein, R. G. 1995: "Observations on the Acheulean occupation site of Ambrona (Soria Province, Spain), with particular reference to recent investigation

Trab. Prehist., 72, N. ${ }^{\circ}$ 1, enero-junio 2015, pp. 41-63, ISSN: 0082-5638

doi: $10.3989 /$ tp. 2015.12143 
(1980 1983) and the lower occupation". Jahrbuch des Römisch-Germanischen Zentralmuseum Mainz 38: 33-82.

Inizan, M. L.; Reduron, M.; Roche, H. y Tixier, J. 1995: Technologie de la pierre taillée. Préhistoire de la pierre taillée 4. Cercle de Recherches et d'Etudes Préhistoriques-CNRS. Meudon.

Mosquera, M. 1995: Procesos técnicos y variabilidad en la industria lítica del Pleistoceno medio de la Meseta: Sierra de Atapuerca, Torralba, Ambrona y Aridos. Tesis doctoral. Universidad Complutense. Madrid. http://eprints.ucm.es/2421/1/AH0024901. pdf (consulta 30-I-2015).

Mosquera, M. 1998: "Differential Raw Material use in the Middle Pleistocene of Spain: Evidence from Sierra de Atapuerca, Torralba, Ambrona and Áridos". Cambridge Archaeological Journal 8 (1): 15-28.

Mourre, V. 2003: "Discoïde ou pas Discoïde? Reflexions sur la pertinence des critères techniques définissant le débitage Discoïde". En M. Peresani (ed.): Discoid Lithic Technology. Advances and Implications. British Archaeological Reports, International Series 1120. Oxford: 1-17.

Ortega Martínez, A. 1992: "Revisión de la industria lítica del yacimiento achelense de Torralba del Moral (Soria)". II Symposium de Arqueología Soriana (1989, Soria). 2: 123-136. Soria.

Ortega Martínez, A. 1994: La industria lítica de Torralba del Moral (Soria). Studia Archaeologica 82, Universidad de Valladolid. Valladolid.

Parcerisas Civit, J. 2006: "El aprovisionamiento de materias primas en los yacimientos de Ambrona y Torralba: la base de recursos". En G. Martínez Fernández, A. Morgado Rodríguez y J. A. Marrero (eds.): Sociedades prehistóricas, recursos abióticos y territorio. Actas de la III Reunión de Trabajo sobre aprovisionamiento de recursos abióticos en la Prehistoria (Granada 2006): 73-86. Granada.

Pérez-González, A; Santonja, M. y Benito, A. 2005: "Secuencias litoestratigráficas del Pleistoceno medio del yacimiento de Ambrona". En M. Santonja y A. Pérez González (eds.): Los yacimientos paleolíticos de Ambrona y Torralba (Soria), Zona Arqueológica 5, Museo Arqueológico Regional. Madrid: 176-188.

Querol, M. A. y Santonja, M. 1979: "Los hendedores en el Achelense de la Meseta española". Sautuola II: 9-39.

Santonja, M. y Pérez-González, A. 2001: “Lithic artifacts from the lower levels of Ambrona (Spain).
Taphonomic features". Proceedings of the I International Congress 'The World of Elephants' (Roma, 2001): 592-596. Roma.

Santonja, M. y Pérez-González, A. 2010: "Mid-Pleistocene Acheulean industrial complex in the Iberian Peninsula". Quaternary International 223-224: 154-161.

Santonja, M.; Pérez-González, A. y Flores, R. 2005: "Torralba, Ambrona y el marqués de Cerralbo. Las dos primeras excavaciones del Paleolítico inferior en España". En M. Santonja y A. Pérez-González (eds.): Los yacimientos paleoliticos de Ambrona y Torralba (Soria), Zona Arqueológica 5, Museo Arqueológico Regional. Madrid: 18-39.

Santonja, M.; Pérez-González, A.; Domínguez-Rodrigo, M.; Panera, J.; Rubio-Jara, S.; Sesé, C.; Soto, E.; Arnold, L. J.; Duval, M.; Demuro, M.; Ortiz, J. E.; Torres, T. de; Mercier, N.; Barba, R. e Yravedra, J. 2014: "The Middle Paleolithic site of Cuesta de la Bajada (Teruel, Spain): a perspective on the Acheulean and Middle Paleolithic technocomplexes in Europe". Journal of Archaeological Science 49: 556-571.

Santonja, M. y Vega Toscano, G. 2002: "La investigación del valle del Manzanares (1862-1975) en el contexto del Paleolítico español". En J. Panera y S. Rubio (eds.): Bifaces y Elefantes. La investigación del Paleolítico inferior en Madrid. Zona Arqueológica 1, Museo Arqueológico Regional de Madrid. Alcalá de Henares: 242-275.

Sesé, C. y Soto, E. 2005: "Mamíferos del yacimiento del Pleistoceno Medio de Ambrona: análisis faunístico e interpretación paleoambiental". En M. Santonja y a. Pérez-González (eds.): Los yacimientos paleoliticos de Ambrona y Torralba (Soria). Zona Arqueológica 5, Museo Arqueológico Regional de Madrid. Alcalá de Henares: 258-280.

Tixier, J. 1956: "Les hachereaux dans 1'Acheuléen nord-africain. Notes typologiques". Congrès Prehistorique Française Poitiers-Angouleme, 1956) XV session: 914 -923. Poitiers-Angoulême.

Tixier, J. y Turq, A. 1999: "Kombewa et al." Paleo 11: $135-143$

Turq, A. 2000: "Paléolithique inférieur et moyen entre Dordogne et Lot". Paléo, Supp. 2.

Vega Toscano, G. 1997: "Recensión de N. Moloney, L. Raposo y M. Santonja (eds.): Non-Flint Stone tools and the Palaeolithic Occupation of the Iberian Peninsula. BAR International Series, 649'. Trabajos de Prehistoria 54 (2): 165-167. 